\title{
A 'Teacher's Guide to the San Francisco Bay Area Geophysics Maps (U.S. Geological Survey GP-1006 and GP-1007)
}

By V.E. Langenheim and Leslie Gordon

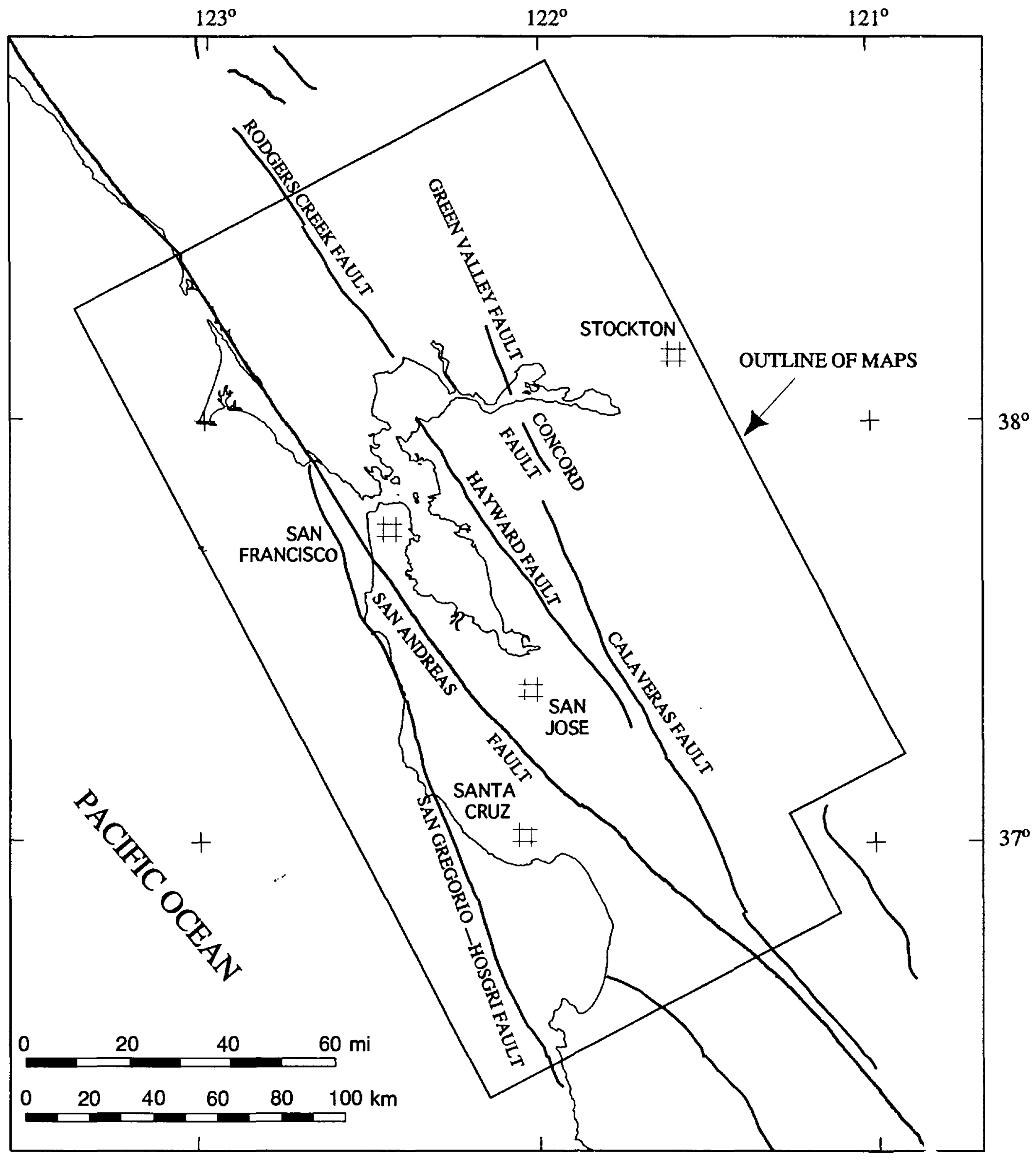

This report is preliminary and has not been reviewed for conformity with U.S. Geological Survey editorial standards or with the North American Stratigraphic Code. Any use of trade, firm, or product names is for descriptive purposes only and does not imply endorsement by the U.S. Government. 


\section{Table of Contents}

Preface

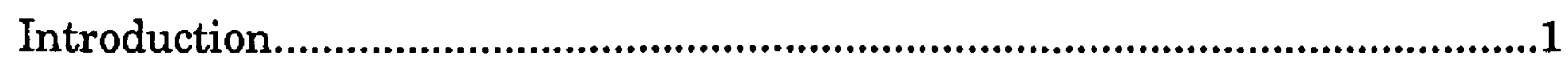

Using geophysics to "see" beneath the Earth's surface...........................1

Box 1.1-Contours-a way of plotting information on a map....2

About the satellite image.................................................................2

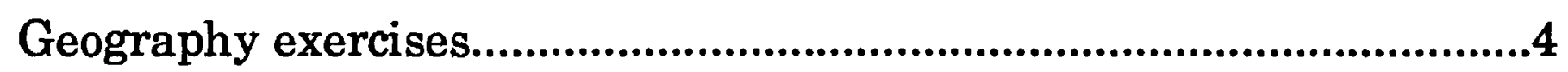

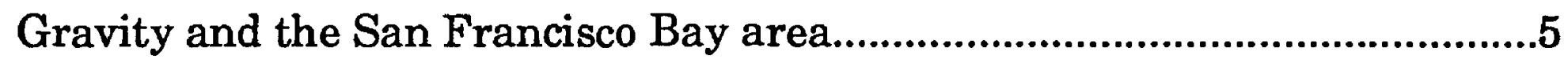

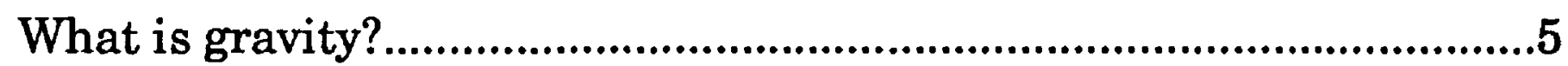

Box 2.1-How do geophysicists measure gravity?......................7

Box 2.2-Isostasy............................................................... 9

A Look at GP-1006: An isostatic gravity map of the Bay area...........10

Box 2.3-Plate Tectonics......................................................11

Gravity and GP-1006 Map Exercises..............................................13

Magnetism and the San Francisco Bay area.............................................16

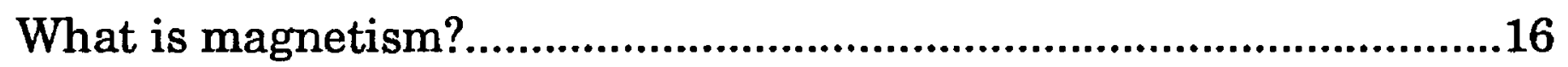

Box 3.1-Playing with magnets..........................................16

Box 3.2-Rock magnetism...................................................18

Box 3.3-Bio-magnetism.....................................................19

Looking at GP-1007: An aeromagnetic map of the Bay area.............19

Box 3.4-How deep is the source of a magnetic anomaly?........20

Magnetism and GP-1007 Map Exercises............................................24

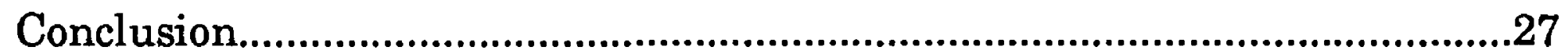

Box 4.1-The Chicxulub Crater (or how gravity and ................27

magnetic data helped find the "smoking gun" that killed the dinosaurs)

Local Field Activities. .28

References/Further Reading................................................................28

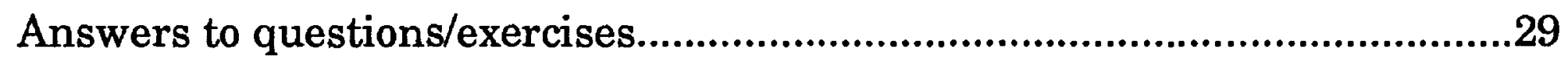

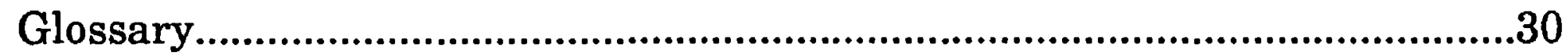

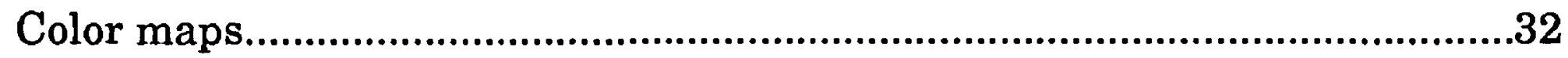




\section{PREFACE}

This publication is a teacher's guide to two U.S. Geological Survey maps that show gravity and magnetic data in contour form superimposed on a LANDSAT satellite image of the San Francisco Bay area. The guide describes the gravity and magnetic fields of the Bay area and discusses row earth scientists use gravity and magnetism to "see" beneath the Earth's surface. Underlined questions within the text are intended to help the teacher formulate exercises in addition to those concentrated at the end of each section. The two maps are U.S. Geological Survey Geophysical Investigations Maps GP-1006 (Isostatic residual gravity map of the San Francisco Bay area, California by Carter W. Roberts and Robert C. Jachens, 1993) and GP-1007 (Aeromagnetic map of the San Francisco Bay area, California by Robert C. Jachens and Carter W. Roberts, 1993). The LANDSAT image with seismicity, but without the geophysical contours, is also available as the Bay Area Earthquakes Poster. You can order these maps from the U.S. Geological Survey by writing

$$
\begin{gathered}
\text { U.S. Geological Survey } \\
\text { Information Service } \\
\text { Box } 25286 \\
\text { Denver Federal Center } \\
\text { Denver, CO } 80225
\end{gathered}
$$

For more information, call (303) 236-7477. It may also be possible to buy the maps at the U. S. Geological Survey Earth Science Information Center located at 345 Middlefield Road, Menlo Park, Califormia; call (415) 329-4.309 for information. 


\section{INTRODUCTION}

\section{Using geophysics to "see" beneath the Earth's surface}

Geologists can map the rocks exposed at the Earth's surface as well as locate where movements along faults have juxtaposed rocks of different composition and history. However, the sources of earthquakes occur at depth, not at the surface. Most of the Earth's mineral deposits and oil ard gas are not exposed at the surface. Geologists cannot directly sample hard, consolidated rocks in areas covered by water or by young sand, silt, and gravel (such as, for example, the San Francisco Bay) except by drilling, which is usually very expensive and depth-limited. However, several different methods of geophysics (literally, the physics of the Earth) allow us to "see" into the Earth and give geologists an indirect and relatively inexpensive "picture" of the rocks beneath our feet. The different geophysical methods measure changes in certain physical properties of rocks. For example, the seismic refraction method measures the velocities of energy waves created by an explosion or an earthquake in order to infer the kinds of rocks or geolngic structures in that area. Electrical methods measure how easily electric currents or electromagnetic waves travel through rocks. Two of the many techniques used by geophysicists, gravity and magnetism, are highlighted in this guide. These data are shown by white contour lines (see box 1.1 on contours) superimposed on a satellite image of the San Francisco Bay area. Hachures, the barbs on some of the contours, point towards areas characterized by relatively lower gravity or magnetic values. As an alternative to presenting these data as numbered contour lines, we also show the gravity and magnetic maps in color in order to help the reader visualize the gravity and magnetic fields (see color figures at the end of the pamphlet). Geophysicists often use both styles of presentation to study the gravity and magnetic fields.

\section{ACKNOWLEDGMENTS}

Special thanks to Bob Jachens for support, Steve Ingebritsen and Andy Griscom for technical reviews, and to Laure Wallace (all of the U.S. Geological Survey). Financial support for the production and publication of this report came from the USGS National Earthquake Hezards Reduction Program and the Human Resources Initiative Excellence in Education Progr $7 m$. Thanks also to Carter Roberts (U.S. Geological Survey) for providing the image on the cover. 
Box 1.1 Contours-a way of plotting information on a map

The white lines on map GP-1006 are contours of equal isostatic residual gravity. A contour on this map is a line connecting points of equal gravity, just as a contour on a topographic map is a line connecting points of equal elevation. The white lines on maD GP-1007 are contours of equal magnetic intensity. To illustrate the concept of contours, let's consider a topographic map. Elevation contours are the patterns left on an island in the middle of a lake as the water level recedes (see figure below). The shoreline represents the same elevation all around the island and is a topographic contour line. Suppose now that the water level of the lake should drop two meters and that the position of the former shoreline is marked by a gravel beach. Now there are two contour lines, that of the former shoreline marked by gravel and that of the current lake level, and these two contour lines accurately depict the shape of the island at these two elevations. If the water level should continue to drop in increments of two meters, additional contours would be formed, each accurately expressing the island's configuration at different elevations. Hachures (teeth or barbs) on contours indicate. lows, with the hachures pointing towards lower values. Closely spaced contour lines represent steep slopes on a topographic map whereas widely spaced contours repres int gentle slopes. Instead of elevation, the white lines depict the magnitude of gravity $\mathrm{cn}$ GP-1006 and of magnetic intensity on GP-1007.

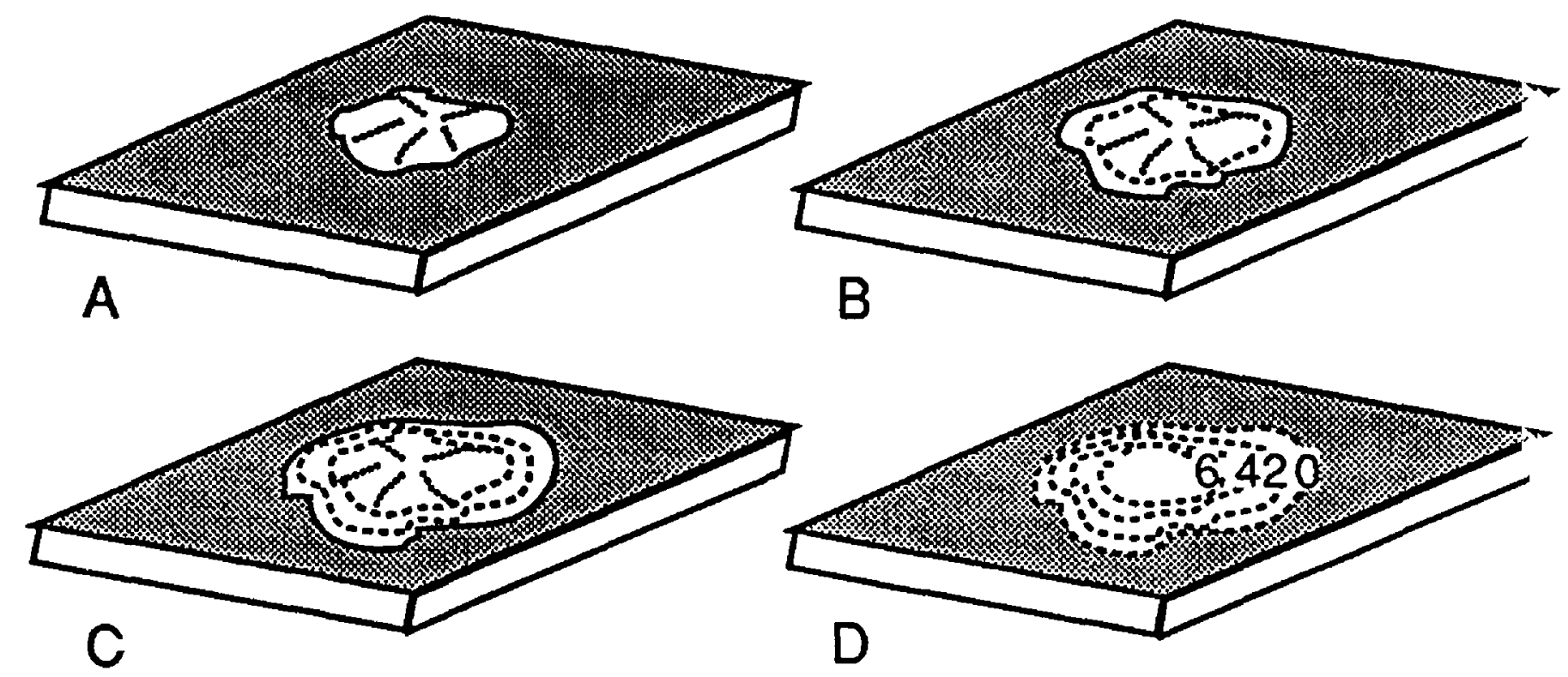

Diagram illustrating the concept of contour lines.

\section{About the satellite image}

This LANDSAT Satellite image that forms the background for the gravity and magnetic maps shows a 50,000-square-kilometer area of central California, extending from Lake Berryessa in the upper right of the poster (north) to Monterey in the lower left (south), and also extending from ab ut 30 kilometers out into the Pacific Ocean on the west to Stockton on the east. 
The image shows the San Francisco Bay area as it looks from an altitude of about 900 kilometers above the Earth.

The satellite image was taken using part of the visible part of the electromagnetic spectrum and also part the infrared part of the spectrum, which is not visible to the human eye. The poster uses false-color imaging to enhance the land forms and surface features. The colors of the features, though brilliant, are not those that we normally see. How many differert colors do you observe? By looking at the distribution of colors and your knowledge of Bay area geography can you guess what the colors mean? The color key is as follows:

Deep red- ground covered by heavy vegetation (for example, the Santa Cruz Mountains near the coast north of Santa Cruz)

Light red-cultivated crops (rectangular areas most abundant in the San Joaquin and Sacramento Valleys, on the right side of the image)

Shades of green-grass-covered areas (east of the San Francisco Pay) and marshy areas (northwest shore of San Pablo Bay)

Turquoise blue - urbanized areas (note the obvious street grids. Red flecks are mostly parks and greenways)

Royal blue- bodies of water (most prominently, San Francisco Bay and the Pacific Ocean)

The bright yellow circles superimposed on the satellite image represent the epicenters of more than 12,000 earthquakes of magnitude 2 or larger that occurred in the San Francisco Bay area between Jan. 1, 1972 and Dec. 31, 1989. An epicenter is the point at the Earth's surface directly above the focus, or actual location, of the earthquake within the Earth's crust. The diameters of the circles depict the magnitude of the earthquakes-from the smallest (one millimeter), representing earthquakes of magnitude 2-3, to the largest, an eight-millimeter-diameter circle in the Santa Cruz Mountains, representing the 7.1 magnitude Loma Prieta earthquake of Oct. 17, 198?. 
Note that many epicenters lie along mapped Bay area fault lines, which are shown on the title page.

\section{Geography exercises}

(A) Using a road map or an atlas, find and mark the following geographic localities on the reference map on the title page of this guide: Lake Berryessa, Stockton, the Santa Cruz Mountains, the Diablo Range, Mt. Diablo, the San Joaquin Valley, San Pablo Bay, the Golden Gate Bridge, and the San Francisco Bay Bridge. Can you find your house or schocl on the satellite image? How did you determine your location? What other landmarks do you recognize?

(B) Using a topographic map* of your area, find where you live and go to school. As the crow flies, how far away is your house from your school? What is the difference in elevation between your house and school? What is the approximate latitude and longitude of your house?

(C) What is the contour interval on the GP maps? Looking at GP maps 1006 and 1007, what is the isostatic residual gravity value and magnetic intensity value at your school?

(D) What kinds of patterns can you see looking at the yellow circles? Do all of them correspond to mapped faults (look at the title page of this guide for mapped fault locations)?

\footnotetext{
* You can buy a topographic map from the U.S. Geological Survey. For maps covering the Western Region (Alaska, Arizona, Hawaii, California, Oregon, Nevada, Washington), call the Earth Sciences Information Center located at 345 Middlefield Road, Menlo Park, Califcrnia (415-329-4309). For areas outside of the western region, you can order maps from the I kap Sales office in Denver, Colorado (303-236-7477).
} 


\section{GRAVITY AND THE SAN FRANCISCO BAY AREA}

\section{What is gravity?}

Gravity is one of the most basic forces in nature. The gravitational force of the Sun keeps the Earth in its orbit around the Sun. The Earth also everts a gravitational force due to its mass; on Earth, gravity is the force that pulls us towards the center of the Earth and, thus, helps to define "up" and "down". Sir Isaac Newton, in 1766, described gravity mathematically as that of tr? mutual attraction or force between two bodies that is a function of their masses and the distance between them. The strength or magnitude of gravity depends directly on the mass of the two bodies and inversely on the square of the distance between them. Newton proposed that the gravitational force, $F$, between two masses, $m_{1}$ and $m_{2}$, could be written as

$$
\mathrm{F}=\gamma \mathrm{m}_{1} \mathrm{~m}_{2} / \mathrm{d}^{2}
$$

where $d$ is the distance between the two masses and $\gamma$ is the universal gravitational constant, a number that is the same everywhere. Mass is a fundamental property of the substance making up a particle or object. Your weight, on the other hand, is the force that you experience as a result of the gravitational attraction between your mass and that of the Earth (or the Moon or wherever you happen to be at the time). You weigh more on the Earth than on the Moon, but your mass is the same in both places. The greater your mass and/or the greater the mass of the other body, the greater the attraction and the more you weigh. You also weigh more if you are closer to the other body (smaller d).

What geophysicists measure is the gravitational acceleration, $\mathrm{g}$, due to the mass of the Earth. Galileo Galilei, in 1592, showed that the velocity of all objects increases or accelerates at the same rate if dropped from the same starting point with no air resistance. If you drop a rock down a well, the rock falls, accelerating at a rate of about $980 \mathrm{~cm} / \mathrm{s}^{2}$ (centimeter per second per second) or $980 \mathrm{Gal}$ ( $1 \mathrm{~cm} / \mathrm{s}^{2}$ equals $1 \mathrm{Gal}$, named in honor of Galileo) or $1 \mathrm{G}$. This means that during each second of free fall, the velocity or speed of th ? rock increases by $980 \mathrm{~cm} / \mathrm{s}$. Often scientists and engineers talk about "G's" when referring to the accelerations that one experiences in an elevator or a roller coaster or that buildings experience during an earthquake. Geophysicists measure $\mathrm{g}$ in units of milliGals ( 1 milliGal or $\mathrm{mGal}$ equals 
$1 / 1000 \mathrm{Gal}$ ) because they are looking for very small changes in $\mathrm{g}$ due to the changes from place to place in the density of the rocks in the crust of the Earth (to depths of $30 \mathrm{~km}$ or more).

How does density relate to mass? Density is directly proportional to mass, $m$, since density, $\rho$, is defined as

$$
\rho=m / V
$$

where $\mathrm{V}$ is volume. The higher the density of an object, the more mass it contains within its volume. For example, a liter of water weighs far less than the same volume of mercury. Rocks can have different densities and geophysicists can isolate the small changes in $\mathrm{g}$ caused by the density distribution of rocks below the Earth's surface with very precise measurements of $\mathrm{g}$. Table 1 is a list of typical densities of rocks exposed in the San Francisco Bay area.

The value of gravitational acceleration, $g$, is not constant everywhere on the surface of the Earth, but depends on several factors including:

(1) the distance to the center of the Earth (the Earth is not a perfe :t sphere, being flattened at the poles, and the distance to its center is also affected by the elevation of the Earth's surface),

(2) the Earth's rotation,

(3) the irregular distribution of land above (or water below) sea-level (topography),

(4) the time-varying attraction between the Earth and the sun and moon (and the tides in the oceans and even in the solid Earth that are caused by this attraction), and

(5) the irregular distribution of different rocks with different densities inside the Earth.

For any place on the Earth's surface at any specific time, we can predict quite accurately the effects on $\mathrm{g}$ of all the factors listed above, except for the ef iacts of the different rock types because, in most places, we do not know very much 
Box 2.1 How do geophysicists measure gravity?

Geophysicists measure gravity using a gravity meter (or gravimeter). There are two different kinds of gravity meters used today. One kind of instrument measures relative changes in $\mathrm{g}$, rather than the actual value. These instruments often use a mass on the end of a spring to measure changes in $\mathrm{g}$ (see figure below). The stronger $\mathrm{g}$ is, the longer the spring becomes. These instruments are kept at a constant temperature so that the properties of the spring do not change. This kind of instrument weighs about $10 \mathrm{~kg}$ and requires about $3-5$ minutes to measure $\mathrm{g}$ with a precision of $0.01 \mathrm{mGal}$.

The other kind of gravity meter (not shown) measures the actual value of $\mathrm{g}$ and is called an absolute gravimeter. It measures very accurately how fast a small mass falls by bouncing a laser beam off the falling object. To reduce friction on the mass, the mass is dropped within a chamber which also falls. This procedure is repeated abort. 1000 times to achieve a precise measurement of $\mathrm{g}$. This instrument, in contrast to the other kind of gravimeter, weighs about $250 \mathrm{~kg}$ and takes about 12 hours to obtain a measurement of $g$ to a precision of 0.01 to $0.001 \mathrm{mGal}$.

Questions

1. What percentage of the Earth's gravitational field is a gravity meter capable of measuring?

2. What happens to a spring as it is heated? Is it easier to elongate the spring whez it is cold or warm?

3. What are the advantages of using an absolute gravimeter? What are the disadvantages?

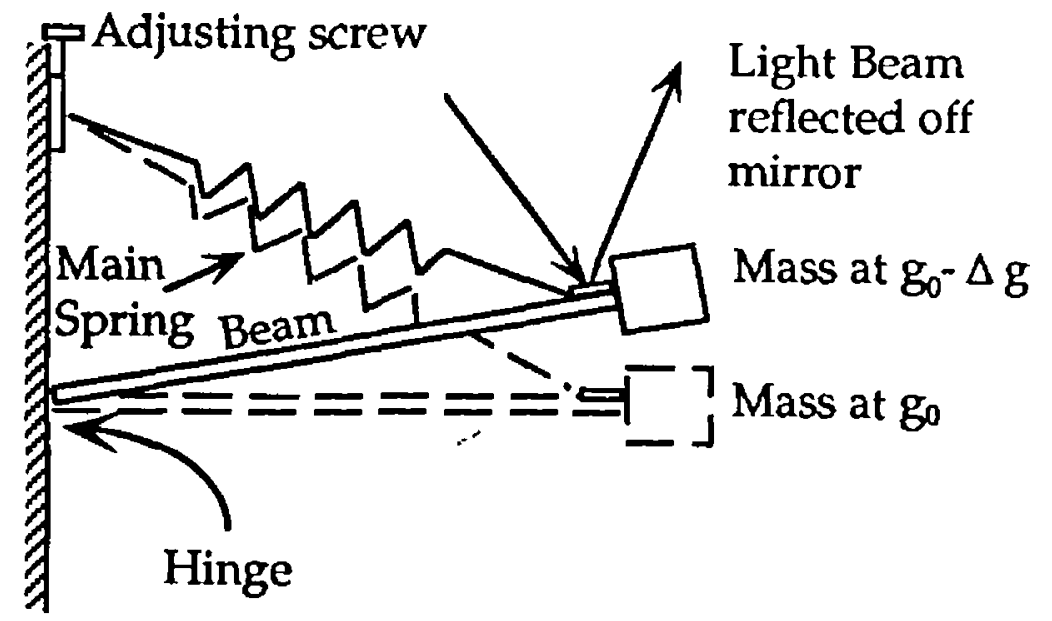

Schematic drawing of how a gravimeter measures relative changes in gravity. $\Delta \mathrm{g}$ is the change in $\mathrm{g}$ relative to $g_{0}$

about the types or locations of rocks beneath the ground surface. This information is exactly what earth scientists seek. The theoretical value of $g$ corrected for factors 1-4 listed above can be subtracted from the actual, measured value to infer the distribution of different rocks inside the Earth. 
The difference between the actual and theoretical value is called a Boug rer gravity anomaly (Pierre Bouguer was a French geophysicist who laboriously measured a degree of latitude in the Andes in the 1700s; it took seven years!). On map GP-1006, the gravity measurements are also corrected for the broad, gentle effects of isostasy (thus the term isostatic residual gravity; see bcx 2.2) so that the anomalies predominantly reflect density changes in the upper and middle crust (approximately the upper $15 \mathrm{~km}$ ). After the effects of factors 1-4 and isostasy have been subtracted, the remaining (or residual) gravity values reflect the density of the underlying rocks and can be used to help determine what kinds of rocks are located below the surface.

Table 1. Typical densities for Bay area rocks

\begin{tabular}{|c|c|c|c|}
\hline Rock type* & age** & range $e^{* * *}$ & average*** \\
\hline Quaternary sediments (Qs) & $0-2$ & $1.7-2.2$ & 2.0 \\
\hline $\begin{array}{l}\text { Cenozoic volcanic rocks }{ }^{\mathrm{M}} \\
(\mathrm{Crv})\end{array}$ & $0-65$ & $2.2-2.7$ & 2.5 \\
\hline Tertiary sedimentary rocks (Ts) & $2-65$ & $2.2-2.6$ & 2.4 \\
\hline Cretaceous sedimentary rocks $(\mathrm{Ks})$ & $65-140$ & $2.6-2.7$ & 2.65 \\
\hline $\begin{array}{l}\text { Cretaceous and Jurassic } \\
\text { Franciscan Complex (KJf) }\end{array}$ & $65-210$ & $2.6-2.8$ & 2.67 \\
\hline $\begin{array}{l}\text { Mesozoic igneous rocks (M/zi) } \\
\text { (includes gabbro }{ }^{M} \text { ) }\end{array}$ & $65-250$ & $2.7-3.0$ & 2.8 \\
\hline Mesozoic metamorphic rocks $(\mathrm{M} / \mathrm{m})$ & $65-250$ & $2.6-2.8$ & 2.7 \\
\hline Mesozoic granitic rocks (Mzg) & $65-250$ & $2.6-2.8$ & 2.67 \\
\hline Mesozoic serpentinite ${ }^{M}$ (M/zsp) & $65-250$ & $2.2-2.8$ & 2.4 \\
\hline
\end{tabular}

* See explanation of geologic units at the end of this guide.

**Millions of years ago

*** grams/cubic centimeters

$M$ magnetic

Higher residual gravity values are found over rocks that are more dense (in other words, they have more mass) and lower gravity values are found over rocks that are less dense. Look at Table 1 . De you see any patterns to the densities according to age or composition? In general, younger rocks are less dense than older rocks, and sedimentary rocks are less dense than metamorphic or igneous rocks. Why do younger rocks tend to be less dense than older rocks? As sediments are laid down, older layers are buried by 
Box 2.2 Isostasy

In the mid 1800s, British surveyors discovered a discrepancy of $150 \mathrm{~m}$ in horizontal distance between 2 stations in India $625 \mathrm{~km}$ apart, as measured by surveying and as calculated from astronomical readings. J.H. Pratt, a British physicist, explained the discrepancy by arguing that the mass of the Himalaya Mountains would deflect the plumb line (a way of measuring vertical) northward at each station, but more at the station closer to the Himalayas. However, Pratt's estimate of how much the mass of the Himalayas should deflect the plumb line was 3 times the amount actually measured. G.B. Airy, another British scientist, explained the difference by theory of isostasy. He proposed that the Earth's crust is floating on a dense, plastic substratum and that the extreme elevation of the Himalayas is supported by a root of low-density rocks, much as an iceberg is supposed by its underwater mass. Pratt later agreed that the crust is in a state of flotational balance, but hypothesized that topography is supported by a crust having a uniform thickness below sea-level, but varying density (e.g., a balsa wood plank will float higher than an oak plank).

Evidence supporting the idea of isostasy comes from Scandanavia and the Hudson Bay lowlands of North America, where the land is slowly rising. During the Pleistocene ice ages, the land there was once covered by a sheet of ice 3 kilometers thick, weighing down the crust. The ice melted some tens of thousands of years ago, and the crust is still rising slowly because isostatic balance has not yet been attained.

Worldwide gravity measurements indicate that some form of isostatic compensation exists over most of the Earth's surface, although the density distribution within the crust is far more complicated than suggested by either the Airy or Pratt models.

\section{AIRY'S MODEL}

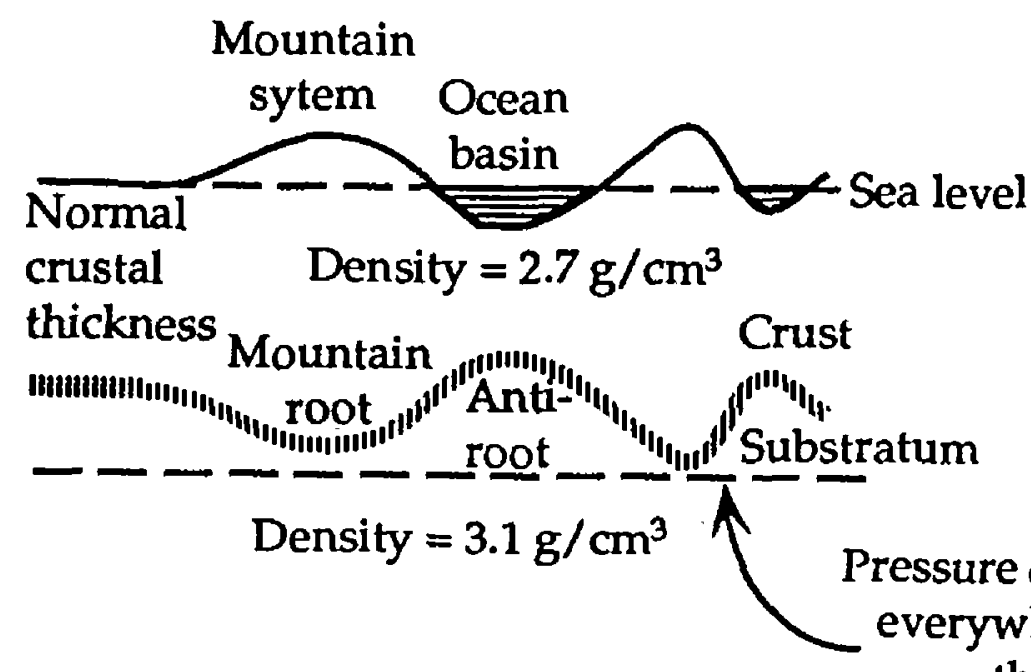

\section{PRATT'S MODEL}

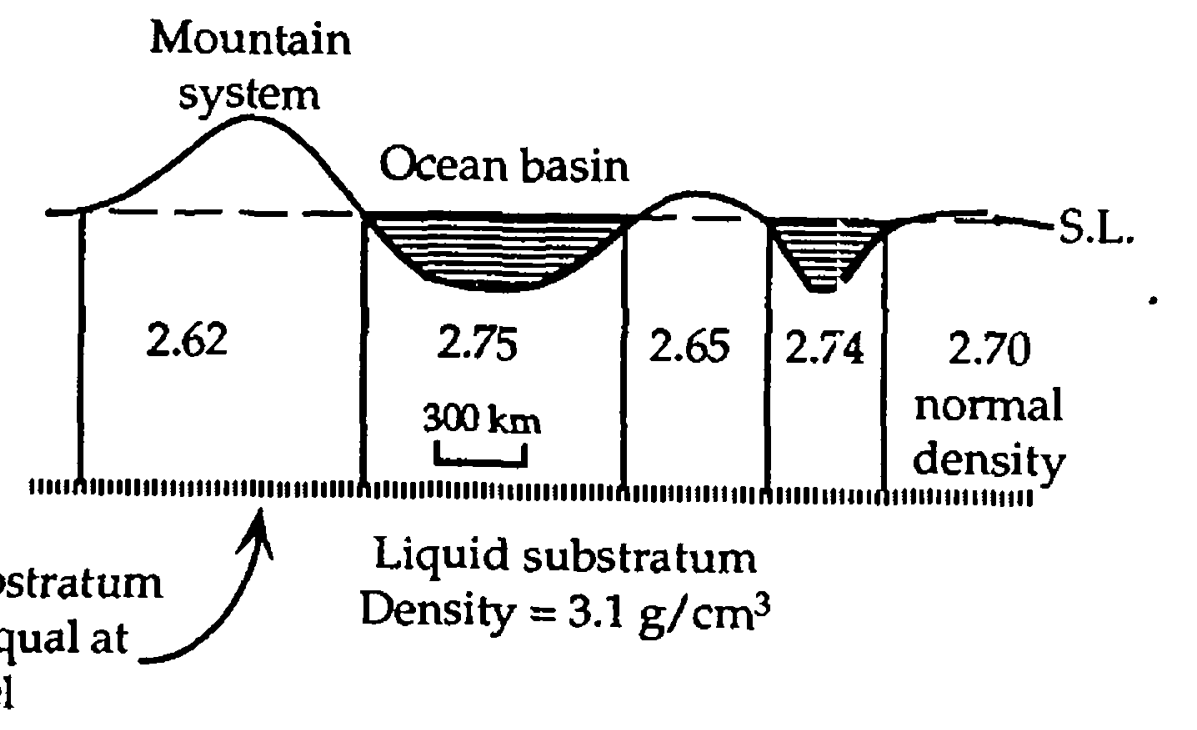


younger layers. The older layers become more compressed by the weight of younger and younger layers of sediments, squeezing out water or air from the pores or spaces between the sediment grains and increasing the rock's density. Why are sedimentary rocks generally less dense than igneous or metamorphic rocks? Rock density is also a function of composition. Compare the densities of the rocks of units Mzg and Mzi. Both of these geologic units consist of igneous rocks, but are characterized by different compositions. Granitic rocks are composed of minerals rich in silicon and aluminum ( $f \in l s i c$ ), whereas the igneous rocks grouped under unit Mzi tend to be rich in iron and magnesium ( $m a f i c$ ). Minerals that contain a lot of silicon and aluminum weigh less than minerals containing iron and magnesium. Many types of sedimentary rocks tend to be enriched in felsic minerals and, therefore, tend not to be very dense. In addition, because of the way metamorphic and igneous rocks form, they tend to have very little pore space and, thus , tr $: y$ usually are fairly dense rocks.

\section{A Look at GP-1006: An isostatic residual gravity map of the Bay area}

Shaded areas on Figure 3 on GP-1006 show some of the prominent gravity highs in the Bay area. After comparing this map with the simplified geologic map (at the back of this guide), with what kinds of rocks do these gravity highs coincide? The gravity highs tend to occur over outcrops of what geologists have named the Franciscan Complex (unit KJf on the geologic map) and over outcrops of plutonic rocks (units $M_{2} \mathrm{i}$ and $\mathrm{M}_{2} \mathrm{~g}$ ). Plutonic rocks are rocks that solidified from molten rock beneath the surface of the Ear' $h$. Geologists believe that the Franciscan Complex is part of former oceanic crust and overlying sedimentary rocks that were scraped up onto North America in a subduction zone (see box 2.3) many millions of years ago and then were smeared laterally along the edge of the continent by faulting along the San Andreas and other faults. Over what kinds of rocks do gravity lows occur (hachured areas)? Are these rocks young or old compared to the rocks trat coincide with gravity highs? Most of the gravity lows occur over Cenozoic sedimentary rocks that have formed in valleys and former seas that once covered parts of the San Francisco Bay area. The magnitude of the gravity low is proportional to the thickness of the low-density sedimentary rocks. If you were an oil-company geologist, how would you use the gravity map to 
The theory of plate tectonics states that the Earth's crust is rigid and is divided into about 12 main slabs or plates that float on an underlying plastic zone. Deformatior occurs along the edges of the plates as they move and grind together. The San Andreas fault forms the boundary between the North American and Pacific plates, along which the two plates slide horizontally past each other (a transform plate boundary). New crust is created along spreading centers, another type of plate boundary where subsea mountain chains that rise above the ocean floor in many of world's oceans. Here new crust is created as the two plates move "spread" away from each other. Iceland is one place where a spreading center is above sea level. Crust is consumed in subduction zones, where the leading edge of one plate dives under another plate (e.g., the Andes on the west coast of South America). Earthquakes, volcanoes, and mountain belts are generally located near the edges of the plates. T) direction and rate of movement (kinematics) of each plate is unique and fairly well known today, but the driving force or forces (dynamics) of the plates are not yet well understood. Plate tectonics implies that the Earth's crust is constantly moving and changing through time.

\section{Exercises}

1. Color the 12 plates shown on the map below. List the 12 plates shown on the map.

2. Using an atlas, locate Iceland, the Andes, and the San Andreas Fault on the map below. Which 2 plates are moving away from each other in Iceland? What is the direction of spreading?

12 major plates and their motions. Spreading centers are shown by arrows pointing away from each other. Subduction zones are boundaries with triangles on the upper or overriding plate.

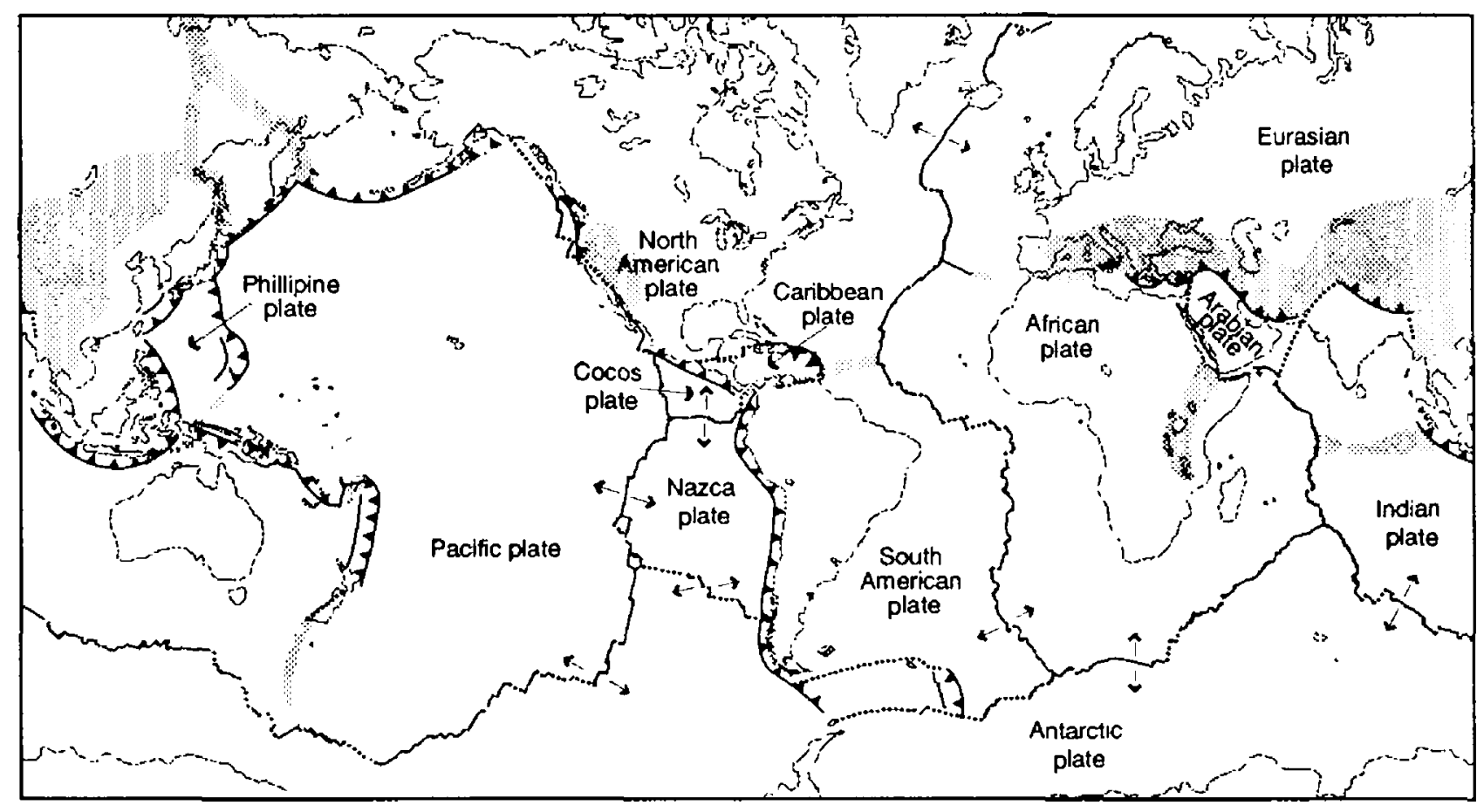

- Divergent plate boundaries-Where new crust is generated as the plates pull away from each other.

m. Convergent plate boundaries-Where crust is consumed in the Earth's interior as one plate dives under another.

Transform plate boundaries-Where crust is neither produced nor destroyed as plates slide horizontally past each other

Plate boundary zones-Broad belts in which deformation is diffuse and boundaries are not well defined. 


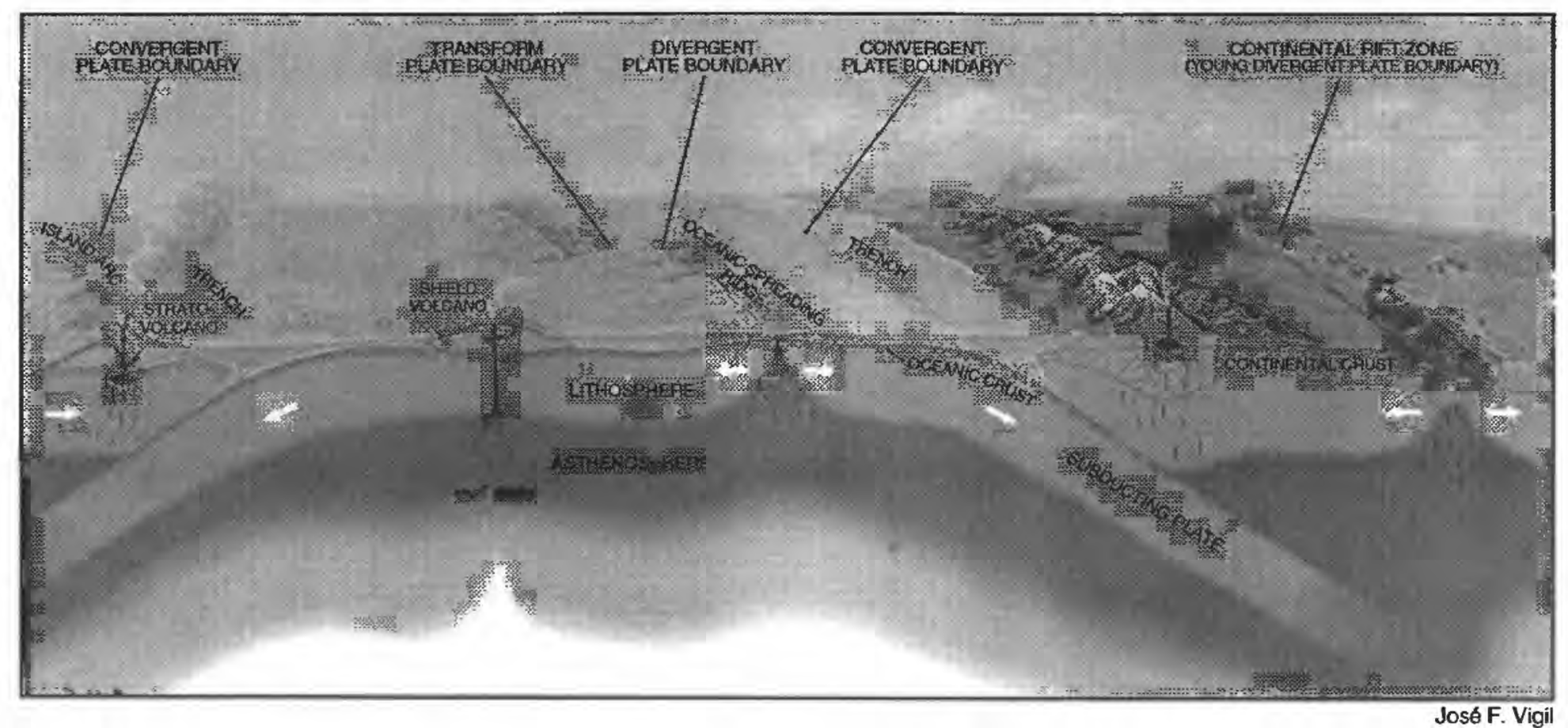

Schematic figure showing movement of the plates (lithosphere) on top of a plastic zone called the asthenosphere. The San Andreas fault is a transform boundary where crust is neither created nor destroyed.

drill for oil or gas in the Bay area bearing in mind that the major oil and gas fields of the world occur within thick accumulations of sedimentary rocks? Where would you drill for oil or gas?

Do clusters of earthquakes (yellow circles) tend to occur over gravity highs or lows? Do earthquakes parallel the gravity contours or cut across them? In many cases, the earthquakes tend to follow closely spaced contour lines. This close spacing of the contours means that the gravity values change abruptly over a short distance (a steep gravity gradient). Because the gravity values reflect rock densities, this means that the density of the rocks varies spatially. Why do the rock densities change spatially? One possible cause for this change is that a fault has juxtaposed rocks of different densities (see Fig. 2 on GP-1006). In areas where geologists cannot map or observe faults at the surface because they are covered by buildings or unconsolidated sediments or where seismologists cannot map the faults because of the lack of earthquakes, one can sometimes use gravity gradients to locate faults. Do you see any gravity gradients within the valleys covered by young sedimentary deposits? Many of the gradients are located along the sides of the larger, flat-bottomed valleys. Furthermore, the way the gravity values change across the fault can tell you if the fault is vertical or sloping 
(dipping). Figure 2 on GP-1006 shows cross sections across vertical and dipping faults and the corresponding changes in gravity that these fault geometries produce. The geometry of the fault is important for predicting the kind of motion produced by faulting. Vertical faults tend to slip horizontally or laterally, whereas dipping faults tend to move up and down. Engineers need to know what kind of motion buildings and bridges would be subjected to during an earthquake so that they can design them to withstand the shaking.

Gravity data also may shed light on geologic structures controlling where and why earthquakes occur along faults in the Bay area. Using a road atlas, locate the San Mateo Bridge in the southern part of the Bay area. You can see the bridge on GP-1006 meeting the East Bay shoreline at the $-18 \mathrm{mGal}$ contour line where the Bay is about $10 \mathrm{~km}$ wide. De you see any clusters of seismicity along the Hayward fault north of the San Mateo Bridge? The biggest cluster of seismicity occurs over an isolated gravity high that top the 0 -mGal contour line. The gravity high tells us that dense rocks underlie this part of the fault. These dense rocks could be acting to concentrate seismicity in this area. Think of water flowing in a stream. If the stream is clear of debris, the water flows without interruption. If you place a log or stone in the stream, the water builds up around the object as it tries to continue alon $r$ its course. Seismologists believe that when a fault ruptures, the rupture of $\rho$ n starts and ends at rough points (asperities) along the fault where the rocks are harder to deform. A block of dense rocks in the fault zone may act similarly to a knot in wood or a log in a stream. Earthquakes will cluster at and around the stronger material.

\section{Gravity and GP-1006 Map Exercises}

(A) Drop a ball or use a pendulum to calculate $\mathrm{g}$. For the first part of this exercise, you will need a stopwatch, a meter-stick, and a ball. How long does it take the ball to drop a vertical distance of $3 \mathrm{~m}$ ? Drop the ball and time how long it takes for the ball to hit the ground. Do this 5 times. What kind of range in times did you measure? Why? The relationship between distance, $(d)$, time $(t)$, initial velocity $\left(v_{0}\right)$, and gravitational acceleration ( $g$ ) is the following:

$$
\mathrm{d}=\mathrm{v}_{\mathrm{o}} \mathrm{t}+1 / 2 \mathrm{gt}^{2}
$$




\section{Since $v_{0} t=0$, $d=1 / 2 g^{2}$}

Using this formula, what value of $g$ did you measure? What are the units of $g$ ?

For the second part of this exercise, you will need a stopwatch, a string, a meterstick, and a ball. Tie the ball to one end of the string. Hang the string so that the ball can swing freely. Measure how long the string is. Holding the string taut, drop the ball so that it swings back and forth like a pendulum. Measure how much time it takes for the ball to return to its initial position. That amount of time is called a period. Improve your precision by measuring the time for severe 1 consecutive swings and then dividing the time by the number of swings to determine the period. The relationship between period $(\mathrm{T})$, the length of the string (l), and $\mathrm{g}$ is the following:

$$
T=2 \pi \sqrt{(1 / g)}
$$

You have measured $\mathrm{T}$ and $\mathrm{I}$. What values of $\mathrm{g}$ do you measure and how do they compare to the values derived in the first exercise? Describe the sources of error in measuring $g$ this way. Note that neither of these equations depends on the mass of the ball.

(B) Measuring densities of rocks (sandstone vs. gabbro).

For this exercise, you'll need a balance or scale, a sink full of water, and a wire basket. Geophysicists measure densities by using Archimedes' principle. Insteed of weighing the rock and then dividing the weight by the volume that you laboriously measured of an irregularly-shaped rock to get the density, you will weigh the rock in air and then in water. The weight in water reflects the amourt of water displaced by the rock's volume. To weigh the rock in water, first weigh the wire basket by suspending it from the balance so that the basket is completely submerged. Now weigh the rock in the basket. Subtract the weight of the rock in the basket from the weight of the basket to get the weight of the rock in water. To get the density, you divide the weight of the rock in air by the weight in air minus the weight in water, $w_{\mathbf{a}} / \mathbf{w}_{\mathbf{a}}-\mathbf{w}_{\mathbf{w}}$. This method works because the density of water is exactly $1 \mathrm{gram} /$ cubic centimeter. Measure a sedimentary rock, an igneous rock, and a metamorphic rock. How do the densities vary from rock to rock? Why? How do these densities compare with the values listed in Table 1 (make sure you are using the same units!)?

\section{(C) Write out in mathematical form the relationship between} gravitational force, mass, and distance. Newton also described force in a general way: $\mathrm{F}=\mathrm{ma}$, where $\mathrm{F}$ is the force in question, $\mathrm{m}$ is the mass $\mathrm{k}$ ing subjected to the force, and $\mathrm{a}$ is acceleration. You can also write that the gravitational force acting on your mass is $\mathrm{F}=\mathrm{mg}$. Using the two equations for force, calculate the mass of the Earth, if the Earth's radius, $r$, is 6370 $\mathrm{km}$, average $\mathrm{g}$ is $9.81 \mathrm{~m} / \mathrm{s}^{2}$, and $\gamma$ is $6.67 \times 10^{-11} \mathrm{~m}^{3} / \mathrm{s}^{2} \mathrm{~kg}$. Now calculate the average density of the Earth, given that the volume of a sphere is equal to $4 / 3 \pi r^{3}$. How does this average density compare with the densities listed in Table 1 ? 
(D) Assuming that the underlying rock types are the same, would yc n measure more gravitational acceleration on top of $\mathrm{Mt}$. Diablo or at Fisherman's Wharf at the San Francisco waterfront? Why? What are the isostatic gravity values at these two places? Explain why a larger value of $g$ does not always correspond to a larger value of residual gravity.

(E) The shape of the Earth is not a perfect sphere. The Equator is farther from the center of the Earth than are the poles. Would you woigh more at the Equator or at the North Pole? Would you weigh more on an airplane (in level flight) or in space? Why?

(F) Assuming everything else is equal, would a ball drop faster if you were standing on a mountain made of gold or on a mountain made of styrofoam? Why?

(G) Groundwater is an important source of water for agriculture and drinking water. Water under the ground resides in the spaces (pores) between the grains that make up the rocks as well as in cracks. The more pores a rock has, the less dense it will be. Would you expect to find high or low gravity values over very porous rocks? Looking at GP-1006, where would be good places to find groundwater?

(H) If closely spaced gravity contours indicate a fault that has juxtaposed rocks of differing densities, where would you extend the Hayward fault north across San Pablo Bay? 


\section{MAGNETISM AND THE SAN FRANCISCO BAY AREA}

\section{What is magnetism?}

The force a magnet exerts on an iron filing or the force the Earth's magnetic field exerts on the needle of a compass are the most common examples of magnetism. People have known about the phenomenon of magnetism for a long time. The ancient Egyptians described magnetic repulsion in about 600 B.C., and the Chinese have known about the magnetic properties of the mineral magnetite (or lodestone) since at least the 1st century $\mathrm{AD}$. In the western world, magnetism was not described until Neckham did so in 1187. The Earth's magnetic field resembles that of a huge bar magnet (see figure 1). Like all magnets, the Earth's magnetic field is dipolar; in other words, it has two poles, a north pole and a south pole. Iike poles will repel; unlike poles attract (see box 3.1). The Earth's magnetic field is most likely caused by movement of partially molten iron in the Earth's outer core, more than $2900 \mathrm{~km}$ below the surface of the Earth. One model to explain the Earth's magnetic field is the dynamo. In this view, the Earth's magnetic field is a dynamo powered by the Earth's rotation. This dynamn must be coupled in such a way that reversals in the direction of the magnetic field can take place since we observe these field reversals frozen in magn etic rocks (see box 3.2).

Box 3.1 Playing with magnets
Take two bar magnets. Suspend one from a thread so that it remains horizontal.
When it comes to rest, the magnet will line up in a north-south direction. Mark the
end of the magnet that points north. Repeat this procedure for the other magnet.
While one of the magnets is suspended, bring the other magnet nearby. What
happens? If you bring the north poles of the two magnets close, they repel each other.
What happens when you bring the south pole of one magnet close to the north pole cf
the other magnet? They attract. These bar magnets always have a pair of poles. Each
piece of the broken magnet has its own north and south poles. Physicists have tried for
years to "break" the magnet into separate poles (monopoles), but no one has succeed sd
(if someone did, he or she would certainly get a Nobel prize!).

Unlike gravity, a force that always points down towards the center of the Earth, the Earth's magnetic field points in different directions depending on location. The north end of a compass points north, roughly towards the geographic north pole of the Earth, but because opposite poles attract, the compass is actually pointing to the Earth's magnetic south pole (which is 
NOT in exactly the same place as the geographic north pole-see figure 1). The angle between the compass needle and true geographic north (meas'ured horizontally at the Earth's surface) is called the declination . Looking at map GP-1007, what is the magnetic declination in the Bay area? If the needle is free to orient itself in a up-down direction, it will point down in the northern hemisphere and up in the southern hemisphere. The angle between the freely oriented needle and horizontal is called the inclination. A freely oriented compass needle will point straight down at the magnetic north pole, straight up at the magnetic south pole, and horizontally at the magnetic. equator (see figure 1). In the Bay area, the inclination is about $62^{\circ}$.

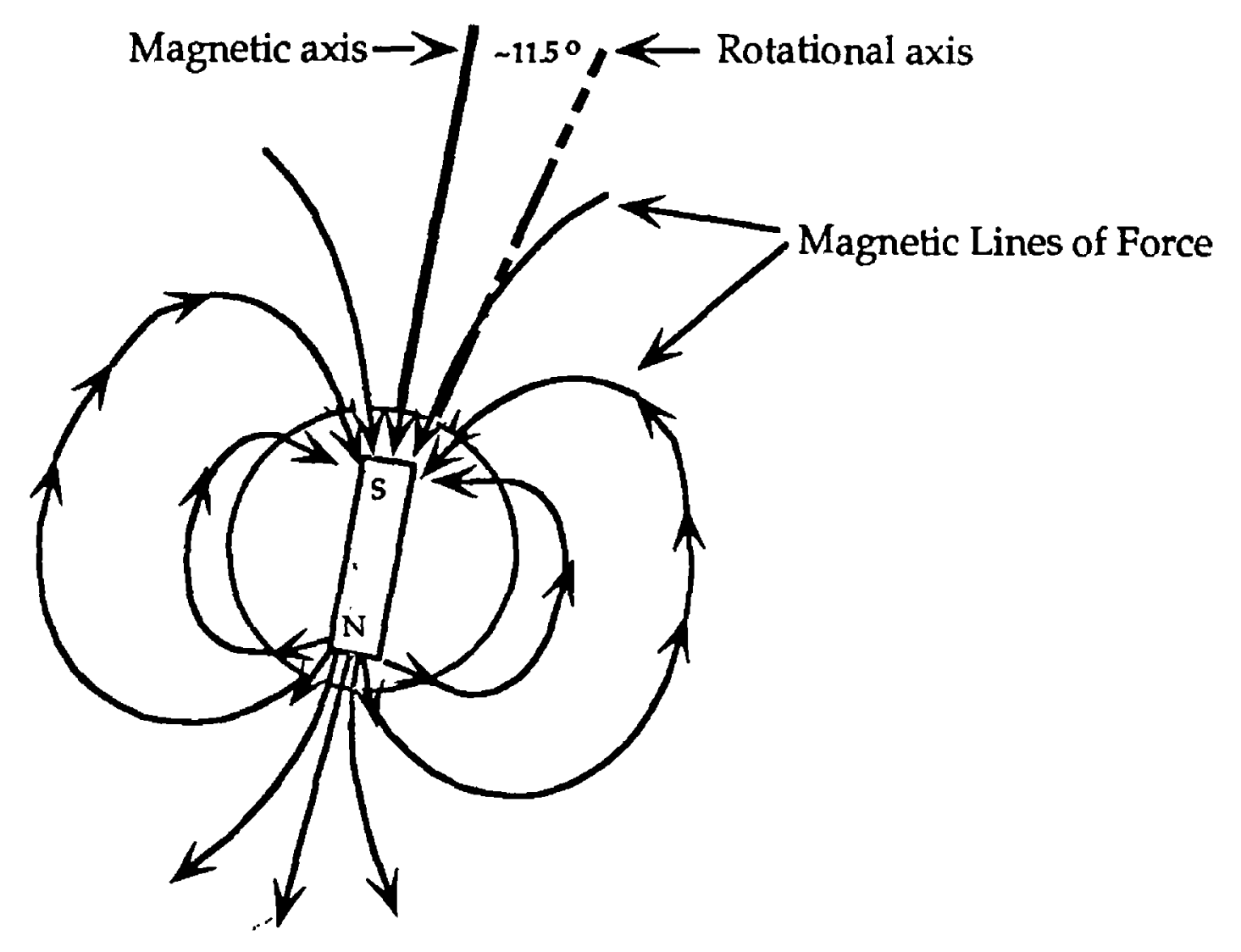

Figure 1. The Earth's magnetic field. The field is similar to that of a bar magnet with the south magnetic pole approximately in the location of the Earth's geographic north pole. The lines of magnetic force are parallel to the Earth's surface only at the magnetic Equator and dip more steeply as the poles are approached. The magnetic and geographic poles do not coincide. 
Box 3.2 Rock magnetism
There are two different kinds of magnetization found in rocks: in duced and remanert.
A rock has induced magnetization if the rock ceases to be magnetic when you place the
rock in an area that has no magnetic field. On the other hand, remanent
magnetization is frozen in the rock when the rock solidifies from molten materials (or
more rarely, when magnetite grains are cemented in place in a sedimentary rock); ir a
field-free area, it will still be magnetic and the direction of the magnetization will be
that of the Earth's magnetic field at the time the magnetization was acquired. Stud :
of remanently magnetized rocks show that the magnetic north and south poles have
flipped back and forth through geologic time. About 730,000 years ago, our ancestors'
compass needle would have pointed south instead of north. On map GP-1007, almost
all of the magnetic anomalies are caused by rocks with induced magnetization.
Exercise
You can take a paper clip or steel nail and cause it to be magnetic for a short time.
Take two paper clips. Do they attract each other? Now take a bar magnet. Hold the
magnet in one hand and carefully put a paper clip next to the magnet's end so that the
magnet's attraction holds one end of the paper clip. Now carefully place a second
paper clip at the end of the first paper clip so that the attraction of the magnet can also
hold it. Attach a third paper clip to the end of the second paper clip. How many pafor
clips can you connect in this magnetic chain? What determines how many paper clips
you can connect in this fashion? Now carefully separate the first paper clip from the.
magnet. What happens? Even without the magnet, the three paper clips will remain
attached to each other for a short period of time. How long did they stay attached?
This exercise helps illustrate how something that is not magnetic can become magnetic
when placed in a strong magnetic field (the magnet's), but, once removed, loses its
magnetization.

Geophysicists measure the Earth's magnetic field intensity or strength in units called nanoteslas ( $\mathrm{nT}$ ) in honor of Nicola Tesla, a pioneering investigator of magnetic phenomena. A nanotesla is one-billionth of a tesla. The Earth's magnetic field strength varies from 25,000 nT at the magnetic equator to 70,000 $\mathrm{nT}$ at the magnetic poles. The magnetic field strength and direction also change slowly with time, and occasionally rapidly during a magnetic storm associated with sunspot activity. Magnetometers can measure the strength of the magnetic field to an accuracy of $0.1 \mathrm{nT}$. Just as with gravity measurements, magnetic measurements can also be corrected for known variations of the Earth's magnetic field, so that the resulting variations in the local magnetic field (magnetic anomalies) depend only on variations in magnetization of nearby rocks. The magnetic anomalies give us a tool for "seeing" these rocks even when they are hidden below the surfare. The force of the Earth's magnetic field is not very strong, but is large encugh 
to magnetize certain kinds of rocks which contain iron and nickel minerels (see box 3.2).

Box 3.3 Bio-magnetism

For centuries, we have used the magnetic properties of lodestone or magnetite to navigate our way around the world. We are not the only animals to take advantage of the directional information that the Earth's magnetic field provides. Researchers have discovered that some kinds of bacteria use the magnetic field to determine which way is up. These bacteria f?rm linear chains of internal magnetite crystals to detect the direction of the Earth's magnetic field. Scientists have discovered that organisms started crystallizing magnetite nearly 2 billion years ago. Tiny magnetite crystals have been found in brains of larger animals, such as pigeons, honey bees, and sea turtles, whose abilities to find their way home has been a fascinating puzzle for years. Magnetite grains have also been found in human brains, although we apparently do not use our internally-grown magnetite to find our way home.

Questions

What sorts of experiments could you devise to test whether an animal uses the Earth's magnetic field to navigate? What other tools do we use to locate ourselves besides a compass? Amazing stories tell of lost pets traveling hundreds of miles to return home. What possible tools do they use?

\section{Looking at GP-1007: An aeromagnetic map of the Bay area}

For map GP-1007, the magnetic measurements were made by magnetometers mounted on airplanes (thus the term "aeromagnetic" uset in the map title). A total of 8 different surveys were flown at different times, at different elevations, and along different flight directions. The measurements have been mathematically adjusted so that it appears that the whole are was flown at the same height above the ground. Although you can measure the magnetic field intensity by walking on the ground, you can cover large areas more quickly if you mount a magnetometer onto an airplane (see figure 2). Airplanes are also farther away from manmade objects, such as powerlines and metal pipes, that are very magnetic and may completely otherwise overwhelm the magnetic anomaly caused by the rocks (see box 3.4).

Because the magnetic field in the Bay area is inclined and does not point straight down, a magnetic rock creates both a magnetic high and a magn tic low. As a rule of thumb for this map, the location of the magnetic high is over the southern edge of the body and the magnetic low sits over the northerm 
edge of the body, if the edges of the body are near vertical (see Fig. 2 on GP1007).

\begin{abstract}
Box 3.4 How deep is the source of a magnetic anomaly?
Like gravity, the magnetic force varies inversely with distance. In general, the deerer the magnetic object, the broader and gentler the resulting anomaly will be.

Alternatively, the shallower the magnetic object, the sharper and narrower the resulting anomaly will be. The strength of the magnetic field, $H$, of a buried sphere. as measured directly over the sphere can be written as
\end{abstract}

$$
H=k\left(r^{3 /} d^{3}\right)
$$

where $r$ is the radius of the magnetic sphere, $d$ is the depth to the center of the sphere, and $\mathbf{k}$ is a constant based on the magnetic properties of the sphere. Let's assume that the sphere has a radius of $100 \mathrm{~m}$. What happens to $H$ in terms of $k$ if we measure directly above the sphere at $\mathrm{d}=100 \mathrm{~m}$ and $400 \mathrm{~m}$ ? Most ground magnetic surveys place the magnetometer on top of a pole $2.4 \mathrm{~m}$ high. Many U.S. Geological Survey aeromagnetic surveys are flown about $300 \mathrm{~m}$ above the ground. The amplitude of th $\mathrm{c}$ magnetic anomaly is much greater when the magnetometer is close to the source.

Now let's see how quickly the anomaly dies off as a function of depth. Below are curves of magnetic field strength for a sphere with a radius of $1 \mathrm{~km}$ buried at depths of $2 \mathrm{~km}$, $3 \mathrm{~km}$, and $4 \mathrm{~km}$. As you can see, the curve for the more deeply buried sphere is gent's and broader than the curve for the shallowly buried sphere.

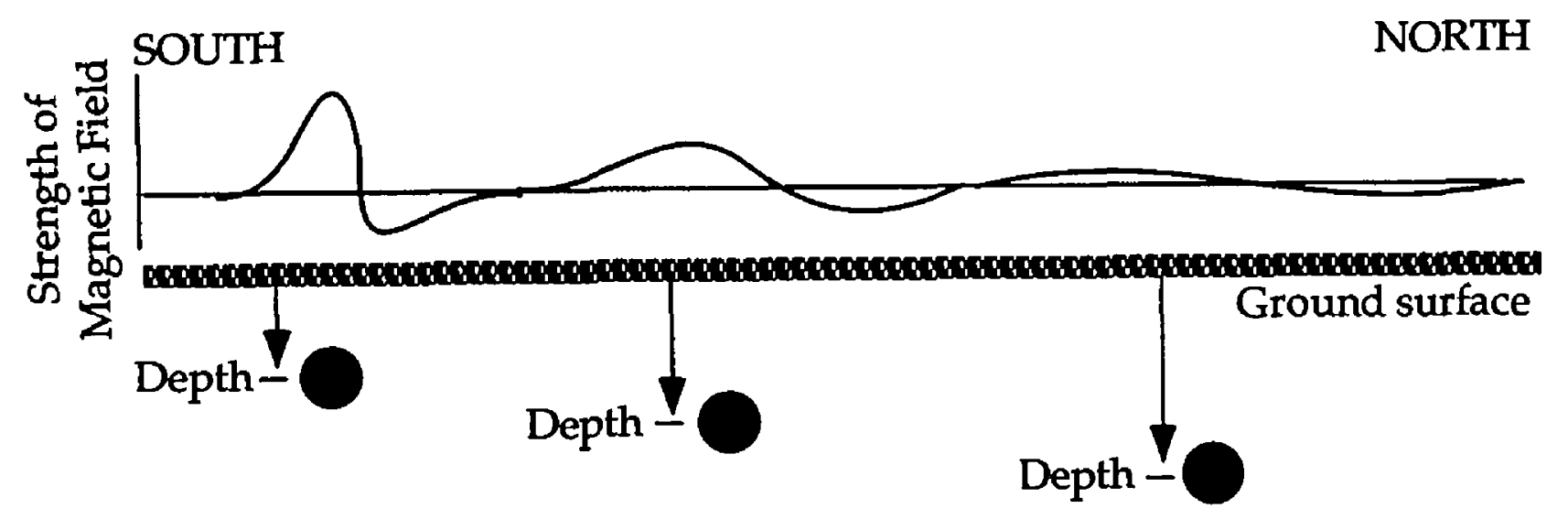

Measurements of many rock samples indicate that sedimentary rocks are generally not magnetic, whereas igneous rocks rich in iron and magnesium (mafic or ultramafic) tend to be very magnetic. After comparing GP-10) 7 with the simplified geologic map. what kinds of rocks correspond to the magnetic anomalies? Look at the region just west of Lake Berryessa (us? a road map or atlas to help locate geographic features). Most of the anomalies in this area are caused by serpentinite (unit Masp on the geologic map). Serpentinite is a type of metamorphic rock caused by low-temperature 
alteration of very mafic (ultramafic) oceanic rocks. Serpentinite is a greasyfeeling, easily deformed rock that tends to occur along fault zones in California and is indeed magnetic. This pale-green rock is also the official state rock of California. Look along the Hayward fault in the vicinity of San Leandro; again, there is a close correspondence between the large, elongated magnetic high and outcrops (exposures) of serpentinite. However, the serpentinite does not crop out at the surface to the extent that its associated magnetic anomaly would suggest. Look at the large magnetic anomaly over Mt. Diablo. Serpentinite is only exposed near the center of the anomaly, but the large magnetic high allows the geophysicist to infer that serpentinite is present below the surficial exposures of the Franciscan Complex (unit KJf) and sedimentary rocks (units $\mathrm{Ks}, \mathrm{Ts}, \mathrm{Qs}$ ), rock types that are generally weakly magnetic.

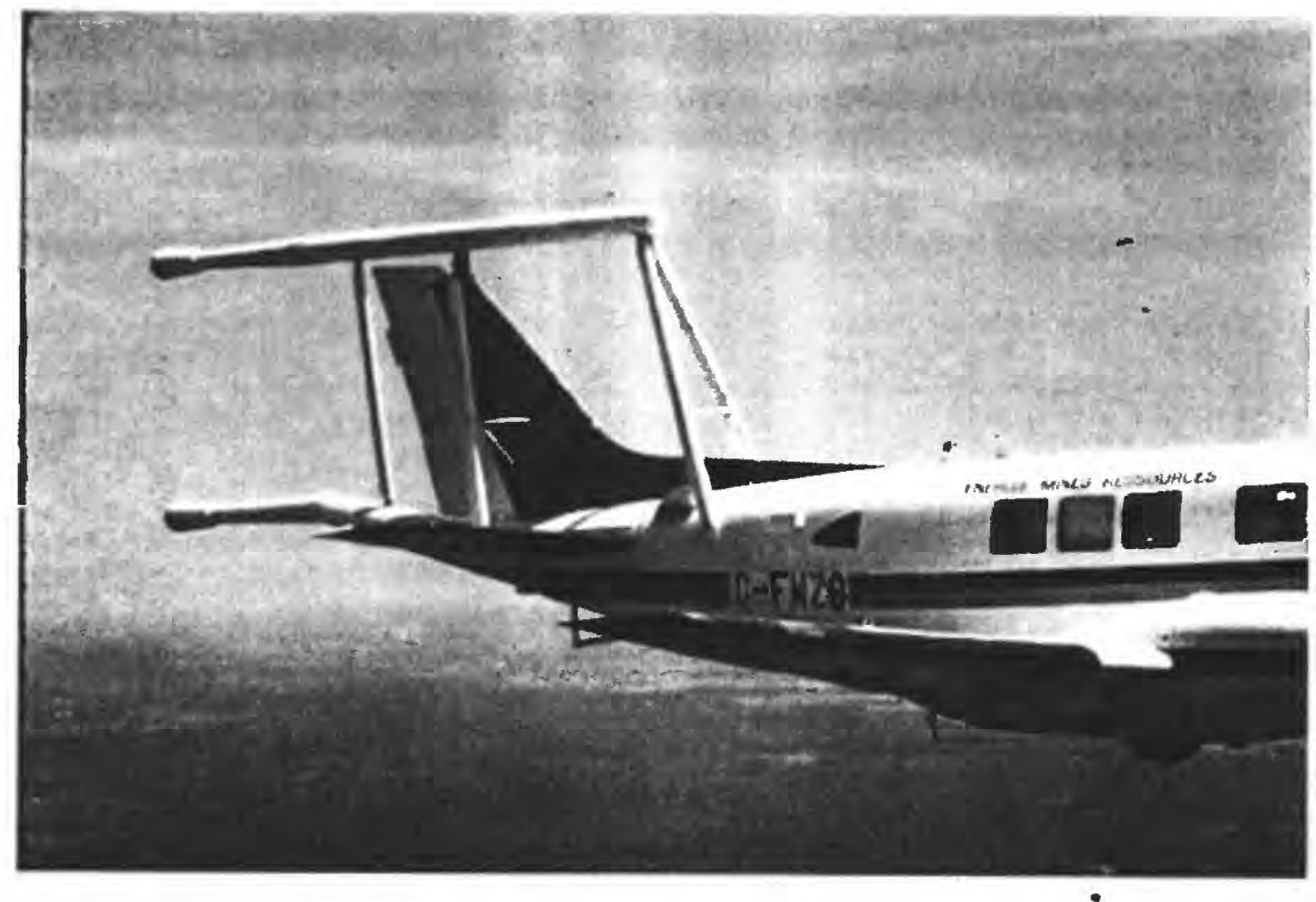

Figure 2.

Two magnetometers are attached to the tail of this airplane. Magnetometers were towed by warships and mounted on airplanes during World War II to search for enemy submarines. They are still used to "hunt" submarines today. 
Two other rock types in the Bay area are capable of producing magnatic anomalies. Look at the magnetic anomalies north of San Pablo Bay and near the southeast corner of the map east of Hollister. Describe the magnetic anomalies in terms of their amplitude and shape. Volcanic rocks, which occur in these areas (map unit $\mathrm{Cz}_{\mathrm{v}}$ ), tend to produce spotty anomalies, in contrast to the serpentinites' elongated magnetic highs. The other rock type capablo of producing magnetic anomalies is gabbro (a mafic igneous rock; part of unit Nai) which is responsible for the magnetic high along the San Andreas fault southeast of Santa Cruz (4 on Fig. 3 of GP-1007).

Not all of the large, broad magnetic anomalies on GP-1007 correspond with surface outcrops of serpentinite, volcanic rocks, or gabbro. The magnetic high in the Santa Cruz Mountains occurs over young sedimentary rocks (unit $\mathrm{Ts}$ ) rather than serpentinite (unit $M_{2} \mathrm{sp}$ ) or volcanic rock (unit $\mathrm{C}_{\mathrm{z} v}$ ). Does this mean that the sedimentary rocks are unusually magnetic? Measurements of its magnetic properties indicate that the sedimentary rocks are only slightly magnetic, not strong enough to cause this anomaly. Thus, geophysicists would conclude that this magnetic high indicates buried mafic or ultram afic rocks in the heart of the Santa Cruz mountains. Some geophysicists infor that the mafic rocks under the Santa Cruz Mountains may be the same gabbro that is exposed along the San Andreas fault southwest of Bakersfield, $300 \mathrm{~km}$ away to the southeast. According to this interpretation, the exp ssure of gabbro would be a sliver comprised of the mafic basement rocks that ras transported many hundreds of kilometers northward along the San And reas fault. Do you see any other large, broad magnetic anomalies that lie over young sedimentary materials? Look along the eastern edge of the color magnetic map. There you'll see the western flank of a broad magnetic high called the Great Valley magnetic high. This magnetic high also suggest : that mafic rocks underlie the young sedimentary rocks exposed in the valley. Geologists believe that these mafic rocks are part of an ophiolite sequence and are a piece of old oceanic crust, now part of the North American continent.

Are the earthquakes concentrated along elongated magnetic highs? In the areas where earthquakes occurred along elongated magnetic highs, the serpentinite is concentrated along fault zones that were seismically active 
between 1972 and 1989. What about linear magnetic highs that do not have yellow clusters (earthquake epicenters)-along them? Are the serpentinites which cause these anomalies marking old, long-dead faults or, more ominously, are these faults just dormant?

To consider the importance of the time interval of the seismicity on the map, let's consider the pattern of seismicity along the San Andreas fault. Many people look at the trace of the San Andreas fault just south of San Francisco on this poster and feel comforted that there are few earthquales, when in fact, this area has one of the higher probabilities for a large earthquake. The presence of so many small earthquakes south of this section suggests that the stress is high along the San Andreas fault. Scientists know that the Pacific plate is sliding to the northwest relative to the North American plate at an average rate of 5 centimeters per year. The faults in this area are merely the surface expression of the edges of these two tectonic plates grinding past each other. The movement along different segments of these faults varies from place to place. Some segments experience relatively smooth, continuous slippage, but other segments undergo jerky movement because they do not slip continuously but instead are locked over tens to hundreds of years, during which time the rocks of the moving plates are deformed elastically near the fault and store energy like a stretched spring. The motion of the plates builds up strain (as stored elastic energy along these faults) until the stress becomes too much, the fault unlocks, and the buil ${ }^{t}$-up pressure is released as an earthquake. Geologists know that the San Francisco area has been rocked with large earthquakes fairly regularly throughout geologic time. The seismicity gap (lack of seismic or earthquake activity) south of Sar Francisco indicates that pressure is building up in this area. Thus, the lack of observed seismicity along the long, linear magnetic anomalies may mean that the faults are very old and dead or, if still alive, that the last earthquake along these faults occurred before 1972, a very short time indeed on the scale of geologic time. Considering that several belts of magnetic anomalies point towards San Francisco and San Jose, information on when these faults last moved is needed in order to assess their earthcuake potential. 
As with gravity anomalies, magnetic anomalies can indicate whether the contact between magnetic and non-magnetic rocks is vertical or not. Find where the offshore part of the San Gregorio-Hosgri fault lies on GP-1007. Note that the seismicity along this fault is fairly scattered, but essentially parallels the magnetic contours. Where do the earthquake epicenters and the mapped location of the fault lie with respect to the magnetic high and low (compare GP-1007 with the color magnetic map)? If the fault were vertiral, where should the earthquakes fall with respect to the magnetic low? The configuration of the magnetic anomaly along the San Gregorio-Hosgri fault suggests that the fault is dipping to the east.

The broad magnetic high in the Santa Cruz Mountains hints at an asperity along the San Andreas fault. Are there many earthquakes within the magnetic high? Describe what happens to the trend of the San Andreas fault in this area. Take a ruler and try to fit one straight line along the San Andreas fault between San Francisco and Hollister on the color magnetic. map. Is it easier to fit the trace of the fault if you draw two straight-line. segments? The magnetic high lies near the intersection of the two straightline segments. Why would the San Andreas fault bend in this area? Gabbro, the inferred source of this magnetic high, can be very strong and resist deformation. It may be easier to deform around this gabbro than to break through the harder, more resistant material. As a result of this bend in the fault, the Santa Cruz Mountains are being formed (figure 3; see exercise $\mathrm{E}$ below).

\section{Magnetism and GP-1007 Map Exercises}

\section{A) Playing with magnets}

Place a bar magnet under a piece of paper. Sprinkle iron filings or used staples around the magnet. What happens to the filings or staples? How do they align themselves with respect to the magnet? They align themselves according to the direction of the magnetic field. At the poles of the magnet, the iron filings are straight up and down; in the middle of the magnet, the filings are aligned paral al to the length of the magnet. Compare the pattern with that shown in figure 1.

Now do a similar exercise in 3 dimensions. You will need clay or play dough, a cylindrical neodymium magnet formed by 2 standard-sized disks $(1 \mathrm{~cm}$ by $1 / 2 \mathrm{~cm}$; available from Dowling Miner Magnetics in Sonoma, California), and used staples. Roll the magnet inside the clay or play doh. Make the diameter of the ball 2 to 4 times the size of the magnet. Now explore the magnetic field of the 
ball by placing used staples on the ball. What happens to the staples? How do they align themselves on the surface of the ball? At the magnetic poles of the ball, the staples stand up vertically. The staples lie flat against the ball at the magnetic equator. Between the poles and the equator, the staples stand up in different angles with respect to a plane tangent to the ball. This angle is called the magnetic inclination. What is the inclination of the staple at approximately the latitude of the Bay area?

(B) Northeast of Point Reyes are some east-west-trending anomalies. Do these anomalies parallel any mapped faults or coincide with rocks rich in iron and magnesium? What is the cause of these anomalies? (clue: look at the specifications of the aeromagnetic survey flown in this area)

(C) Why are the magnetic contours more convoluted (wiggly) over mest of the Bay area but start to smooth out over the Central Valley?

(D) At the average rate of plate motion ( $5 \mathrm{~cm} / \mathrm{yr}$ ), how long will it take Los Angeles (on the Pacific plate) to be opposite San Francisco (on the North American plate) if Los Angeles and San Francisco are about 6.70 $\mathrm{km}$ apart? The last big earthquake in the San Francisco Bay area was in 1906, where at Point Reyes, the Pacific plate moved as many as 6 meters relative to the North American plate in a matter of seconds (for comparison, the Loma Prieta earthquake caused about 1 meter of off ret). How long would it take to move that same amount $(6 \mathrm{~m})$ using the average rate of plate motion?

(E) To visualize what kind of deformation occurs within a bend of the San Andreas Fault, make a copy of figure 3. Cut the paper into sections A and B. For each section cut the paper along the trace of the San Andreas Fault and move the pieces of paper in the direction shown by the arrows. Describe what happens in the area of the bend of the San Andreas for both cases. 


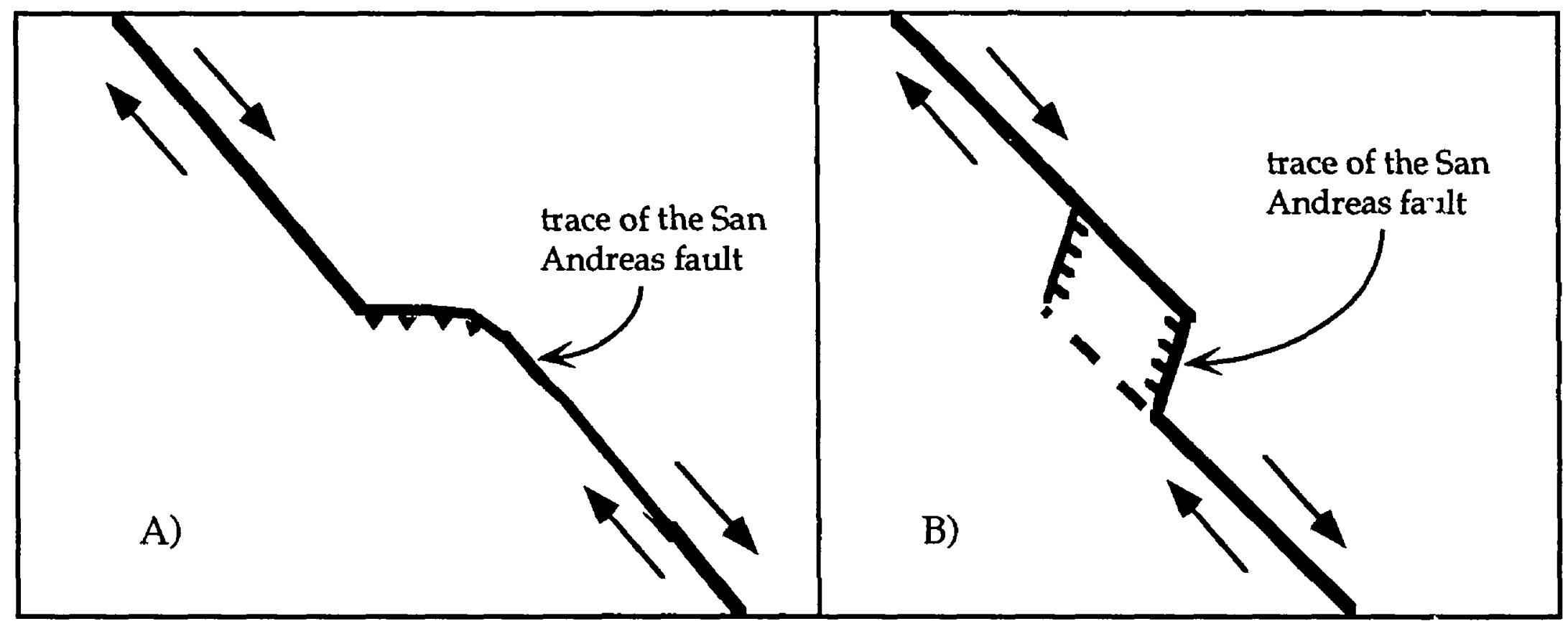

Figure 3. Plan view of the San Andreas fault, showing deformation that occurs the San Andreas fault resulting from a bend or step in the fault. A) The fault steps, or bends, to the left. Barbs on fault within the fault bend indicate compressive faulting. In the area between the fault segments, the arrows showing the relative motion are pointing towards each other. There the Earth's crust is being pushed together. This form of deformation is probably responsible for the formation of the Santa Cruz Mountains. B) The fault steps, or bends, to the right. Teeth on faults within the fault bend indicate extensional faulting. In the area between the fault segments, the arrows point away from each other, causing $\mathrm{tl} \backsim$ Earth's crust to stretch apart and sag. See exercise E at the end of Magnetism and GP-1007 section. 


\section{Conclusion}

In the two previous sections, we discussed gravity and magnetism separately. However, geophysicists often study both of these data sets together in order to further pinpoint the type of rocks present beneath tr 9 Earth's surface. For example, where is the largest isostatic gravity value on map GP-1006? It is located over Mt. Diablo. Looking at Table 1, what rock types have average densities greater than $2.67 \mathrm{~g} / \mathrm{cm}^{3}$ ? At least two rock types on average are dense enough to cause a gravity high. Looking at GP-10SZ are the rocks forming Mt. Diablo magnetic? A large magnetic anomaly coincides with the location of the gravity anomaly. The rock under Mt. I: ablo must be both magnetic and dense. Only one rock type listed in Table 1 (gabbro; unit Mri) fits both of these qualifications and, indeed, gabbro is exposed locally at the top of the mountain.

Study of the gravity and magnetic fields in conjunction with the geology exposed at the surface gives geophysicists a way to "see" into the Earth. With this information and some assumptions, we can help locate faults, mineral and petroleum resources, and groundwater. This information can also g:ve insight into the processes that help shape our world.

Box 4.1 The Chicxulub Crater (or how gravity and magnetic data helped find the "smoting gun" that killed the dinosaurs)

Study of gravity and magnetic fields in the Yucatan Peninsula, Mexico has helped to lo:ate a large crater caused by the impact of a comet or meteorite at the end of the Cretaceous Poriod about 65 million years ago. Some scientists postulate that the effect of this extraterrestrial object colliding with the Earth is responsible for the extermination of many life forms on Earth, including the dinosaurs. Although today the crater does not have an obvious topographic expression (because of the Earth's active weathering and erosional process?s), the gravity and magnetic data allow us to "see" through a kilometer of younger sedimentary rocks to image a buried, $200-\mathrm{km}$ wide crater that was excavated by an extraterrestrial body that may have killed off the dinosaurs.

Further reading

Hildebrand and others, 1991, Chicxulub Crater: A possible Cretaceous/Tertiary boundary impact crater on the Yucatan Peninsula, Mexico, Geology, v. 19, p. 867-871.

Glen, W., July-August 1990, What killed the dinosaurs?, American Scientist, v. 78, p. 354-70.

Alvarez, W., and Asaro, F., October 1990, An extraterrestrial impact, Scientific American, v. 263, p. 78-84. 


\title{
Local field activities
}

\author{
San Francisco--Clyde Wahrhaftig's Streetcar to Subduction, a guide to S?n \\ Francisco geology using public transportation! Published by \\ the American Geophysical Union.
}

East Bay $\quad$--Sibley Volcanic Preserve. Pamphlets describing a self-guided tour are available at the Preserve. For more information, call East Bay Regional Park District (510-635-0135)

Peninsula --Los Trancos Earthquake Trail. Call Midpeninsula Regional Open Space District (415-691-1200) for information or tc request a docent-led tour of the trail. Pamphlets describing a self-guided tour are also available at the Preserve.

--tour of the USGS headquarters in Menlo Park, CA. Call the Earth Science Information Center at (415) 329-4309 for more information.

Point Reyes --Point Reyes National Seashore has assembled an activity guide called "Shake, Rattle, and Roll" that is primarily g?ared for 3 rd to 6 th grades. They have a ranger-led tour of the. Earthquake Trail, which shows the 6-m offset along the San Andreas fault that occurred in the 1906 earthquake. For more information, call (415) 663-1092.

\section{References / Further Reading}

Continental Drift and Plate Tectonics, 2nd ed., by William Glen. Published by GeoResources Associates, 2236 Bunker Hill Dr., San Mateo, CA 94025, 1986, 188 p. Glen describes the basic tenets of plate tectonics and discusses isostasy, paleomagnetism (se? box on Rock Magnetism), and marine magnetic anomalies.

The Earth's Dynamic Systems by W. Kenneth Hamblin. Published by Macmillan Publishing Company, New York, New York, 1989, 576 p. A geology textbook that describes the various processes that shape our planet and how geologists infer these processes from the rock record.

Exploring Our Living Planet by Robert Ballard. Published by the National Geographic Society, Washington, D.C., 1983, 366 p. A beautifully illustrated book that covers the $\mathrm{k}$ asic tenets of plate tectonics with examples from around the world.

How the Earth Works ( 100 ways parents and kids can share the secrets of the Earth) by John Farndon. Published by Dorling Kindersley, Limited for Reader's Digest, 1992, 192 p. 
Janice Van Cleave's Gravity Spectacular Science Projects by Janice Pratt Van Cleave, 1993. Published by John Wiley \& Sons, 88 p.

For the more mathematically inclined and those interested in the physics of gravity and. magnetism

Elementary Gravity and Magnetics for Geologists and Seismologists, by L.L. Nettletor Society of Exploration Geophysicists (SEG) Monograph Series 1. Published by the SET, Tulsa OK, 1971, 121 p. A good general booklet on gravity and magnetics with non-calculus math.

Introduction to Geophysical Prospecting, 4th ed., by Milton B. Dobrin and Carl H. Savit. Published by McGraw-Hill, Inc., 1988, 867 p. Up-to-date textbook on geophysical methods. See chapters 12-17 for gravity and magnetism. Knowledge of calculus very helpful.

Applications Manual for Portable Magnetometers, by S. Breiner. Published by GeoMetrics, Sunnyvale, CA, 1971, 58 p. A good, pictorial guide for interpreting magnetic anomalies.

Geophysical computer programs and data sets

Cordell, Lindrith, Phillips, J.D., and Godson, R.H., 1992, U.S. Geological Survey potentialfield geophysical software version 2.0: U.S. Geological Survey Open-File Report 92-18 16 p., 6 diskettes. Order this from the U.S. Geological Survey, Branch of Distribution, Box 2:286, Mail Stop 306, Denver Federal Center, Denver, CO 80225. For more information, call (303) 236-7477.

National geophysical data grids: gamma-ray, gravity, magnetic, and topographic data for the conterminous United States. A CD-ROM that contains all the programs from Open-File Report 92-18 (listed above) as well as the data grids. Order this (DDS-009) from the U.S. Geological Survey, Branch of Distribution, Box 25286, Mail Stop 306, Denver Federal Center, Denver, CO 80225. For more information, call (303) 236-7477.

\section{Answers to questions/exercises}

\section{GRAVITY SECTION}

Box 2.1

1. Earth's field is 980 or roughly $10^{3}$ Gals; a gravity meter is capable of measuring 0.01 mGal

How many 0.01 mGals in $10^{3}$ Gal? $1000 \times 1000 \times 100$ equals 100 million. A gravity meter is capable of measuring one-hundred-millionth of the Earth's field. Or one-millionth of a percent!

2. A spring becomes less rigid as it is heated. It is easier to elongate the spring wh on it is warm.

3. An absolute gravimeter measures the real value of $g$, but is very heavy and takes a long time to measure $\mathrm{g}$. The other type of gravimeter discussed in Box 2.1 doesn't measure the real value of $g$ (it has to be referenced to a spot where $g$ is known), but it is easily transported and measures $g$ quickly and, therefore, is most often used by geophysicists to cover large areas.

Box 2.3

1. Pacific, Antarctic, Eurasian, African, South American, North American, Indian, Nazca, Phillipine, Caribbean, Arabian, and Cocos plates. 
2. Iceland is located along the boundary between the North American and Eurasian plates. The plates are moving apart in a west-northwest direction (about $60^{\circ}$ west of north).

Map Exercies GP-1006

(C) $\mathrm{F}=\gamma \mathrm{m}_{1} \mathrm{~m}_{2} / \mathrm{r}^{2}$. Mass of Earth $5.9 \times 10^{24} \mathrm{~kg}$; average density $5.5 \mathrm{~g} / \mathrm{cm}^{3}$ or $5500 \mathrm{~kg} / \mathrm{m}^{3}$.

(D) You would measure a higher $\mathrm{g}$ at Fisherman's Wharf because it is closer to the center of the Earth, but the isostatic residual gravity anomaly value is lower there than at Mt. Diablo because Fisherman's Wharf is underlain by rocks of lower density.

(E) You weigh more at the poles because $d$ is smaller. You would weigh less in spece because the airplane is closer to the center of the Earth.

(F) The ball would drop faster on the mountain made of gold. Gold is denser than styrofoam and therefore has more mass.

(G) Low gravity values over sedimentary rocks. Probably not over the Bay because of possible salt water contamination.

\section{MAGNETIC SECTION}

Box 3.4

At $100 \mathrm{~m}, \mathrm{H}=\mathrm{k}$. At $400 \mathrm{~m}, \mathrm{H}=.016 \mathrm{k}$.

Map Exercises GP-1007

(B) No the anomalies don't parallel mapped faults or rock units. Anomalies are parallel to the flightline direction and are artifacts caused by slight differences in the height of the airplane above the land's surface or errors in the flightline locations.

(C) The magnetic rocks are closer to the surface in the Bay Area. The Central Valley is covered by thick non-magnetic sedimentary deposits.

(D) 13,000,000 years! About 120 years of movement.

\section{Glossary}

anomaly A measurement value that is greater (positive anomaly) or smaller (negative. anomaly) than the predicted or expected value at a particular place.

asperity A bend or bump in a fault plane that inhibits release of earthquake energy.

Seismologists believe that great earthquakes can occur when the strain is so great that the released energy of the earthquake can break through or across the irregularities or asperities on the fault surface.

contour A line connecting points of equal amount or value. Contours are a way of plotting information on a map.

density Mass of an object divided by its volume. A rock's density is dependent on what it is made of and how tightly packed the individual grains that make up the rock are.

dynamo A device that converts mechanical energy into electric or magnetic energy.

felsic An adjective to describe silica- and aluminum-rich rock compositions (such as a granite). Felsic rocks consist mostly of feldspars and quartz (silica or silicon dioxide), two common rock-forming minerals. Rocks that have felsic compositions tend to be light-colored.

gradient A change in a given property over a certain distance. A steep gradient indicates that the magnitude of a property (e.g., gravity) changes a large amount over a small distance.

infrared That part of the electromagnetic spectrum with wavelengths larger than abo't 0.7 nanometers and less than about 1 millimeter. One particular region of the infrared spectrum 
is called thermal infrared. We cannot see wavelengths between 8 and 14 nanometers, but we can sense that objects emitting thermal infrared radiation are warm.

isostasy The theory that the large blocks of the Earth's crust float on a substratum in the mantle; that the crust tends to attain a state of floating balance with respect to the meterial beneath it.

mafic An adjective to describe iron- and magnesium-rich rock compositions (such as $\varepsilon$ gabbro or a basalt). Very iron- and magnesium-rich rocks are called ultramafic. Rocks that are mafic in composition tend to be dark-colored.

magnetic poles The two areas at opposite ends of a magnet which show greatest magnetic force. The lines of magnetic force leave the magnet at the south or negative pole and c'urve around to enter the north or positive pole.

mass The amount of substance or material making up an object or body. For example, the mass of your body is the same on Earth as it would be on the moon, even if the amount of pull on you is different.

ophiolites Masses of igneous rocks rich in iron and magnesium (basalt, gabbro, and ol : vinerich rocks) which have apparently been moved as wedges and slivers; their structure and composition suggest that they may be pieces of the uppermost mantle or ocean-floor cr ast which broke from descending plates and were thrust upward into overlying rocks.

Ophiolites, therefore, are believed to lie along the sites of former subduction zones and mark the line along which continents collided to form mountain ranges.

seismicity Earthquake activity

serpentinite A rock composed of serpentine, a mineral which has a greasy luster, soap: feel, and is commonly green, greenish-gray, greenish-yellow, or , less often, brown, black, or white. Serpentine is formed by the metamorphism or alteration of magnesium silicate minerals, such as olivine. 

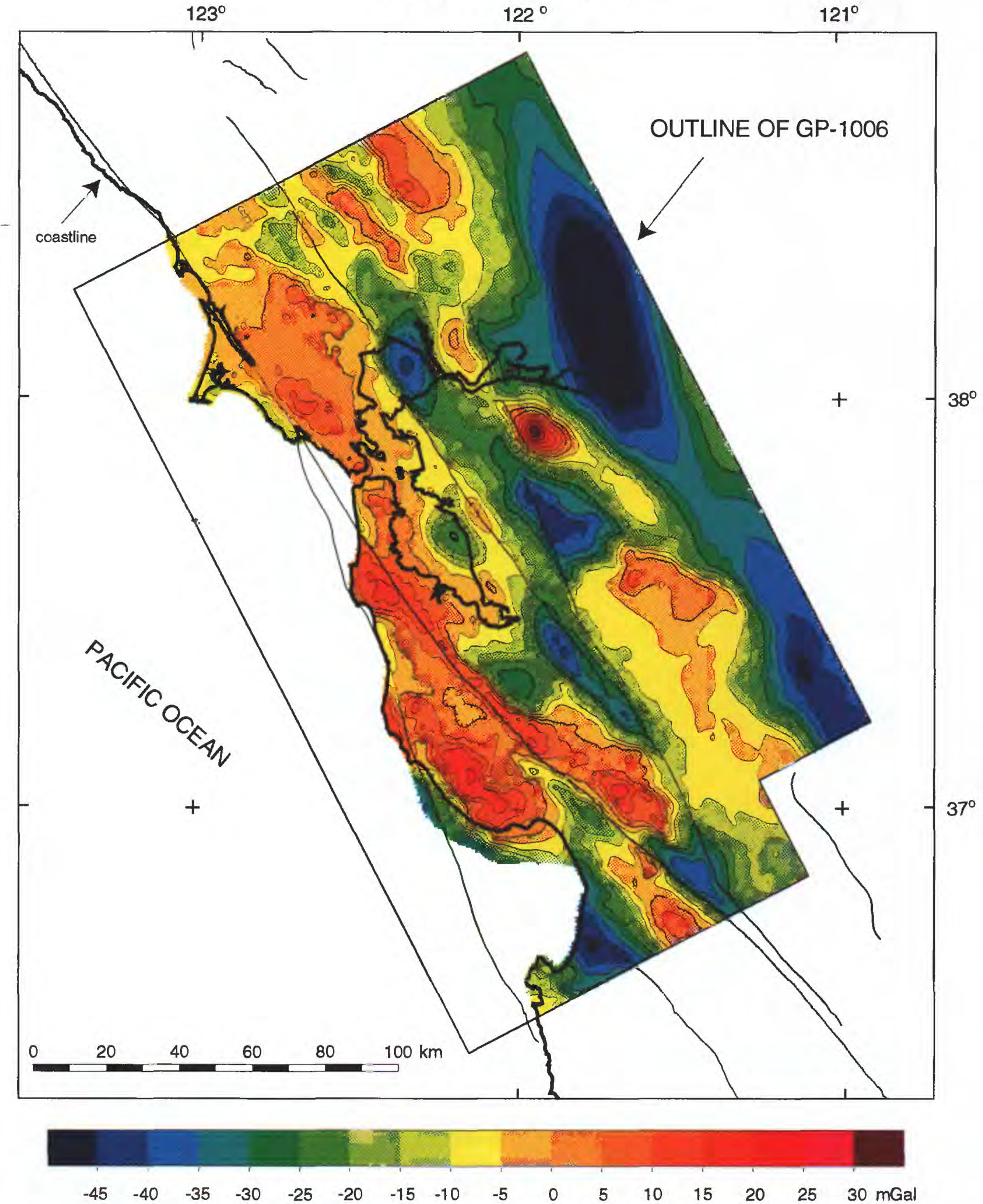

This color gravity map is based on the same contour information as GP-1006, but has color to help guide your eye to gravity highs and lows. The contour color interval is $5 \mathrm{mGal}$. 


\section{COLOR MAGNETIC MAP}
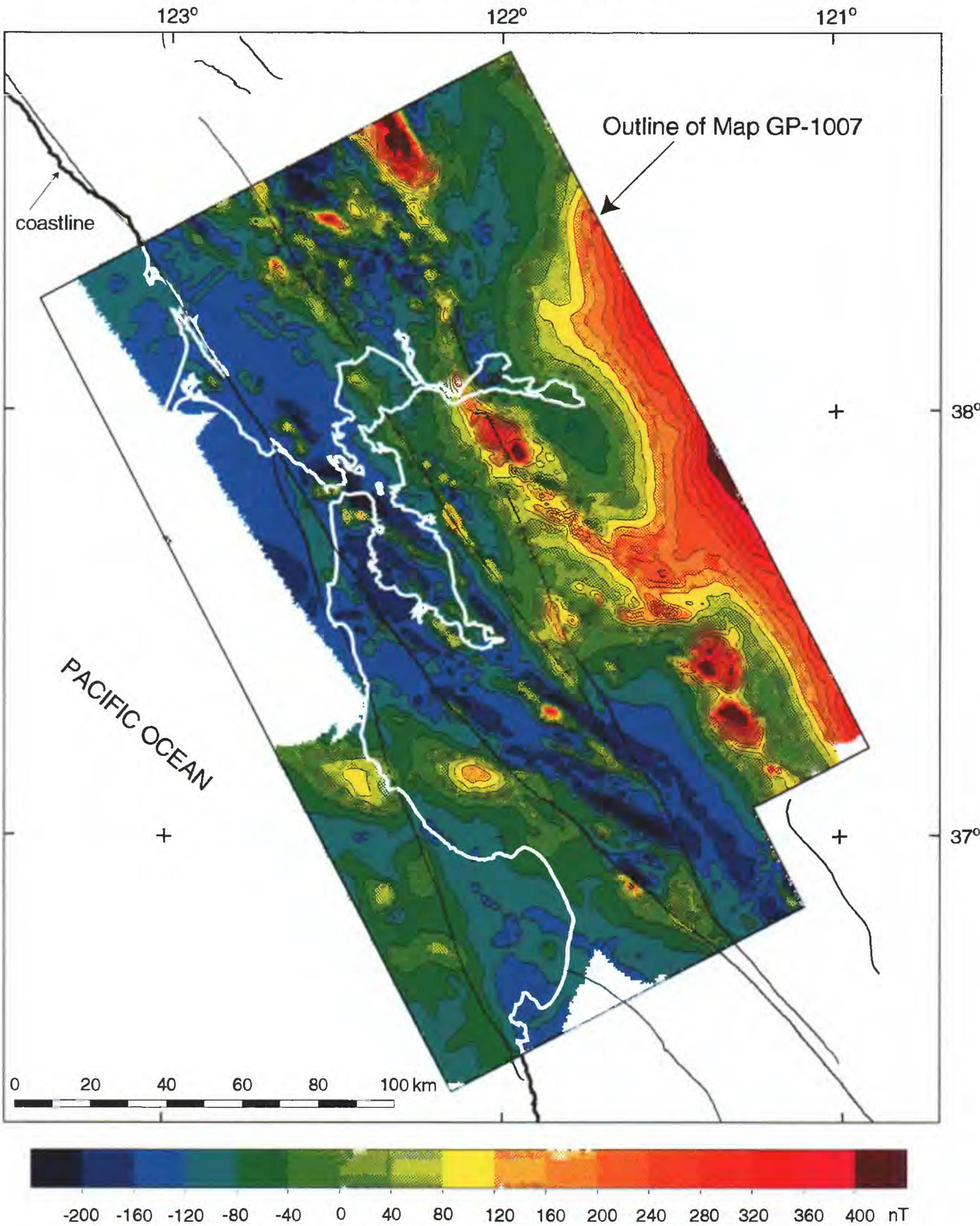

This color magnetic map is based on the same contour information as in GP-1007, but has color to help guide your eye to magnetic highs and lows. The contour color interval is 40 nanoteslas (nT). 


\section{COLOR GEOLOGIC MAP}

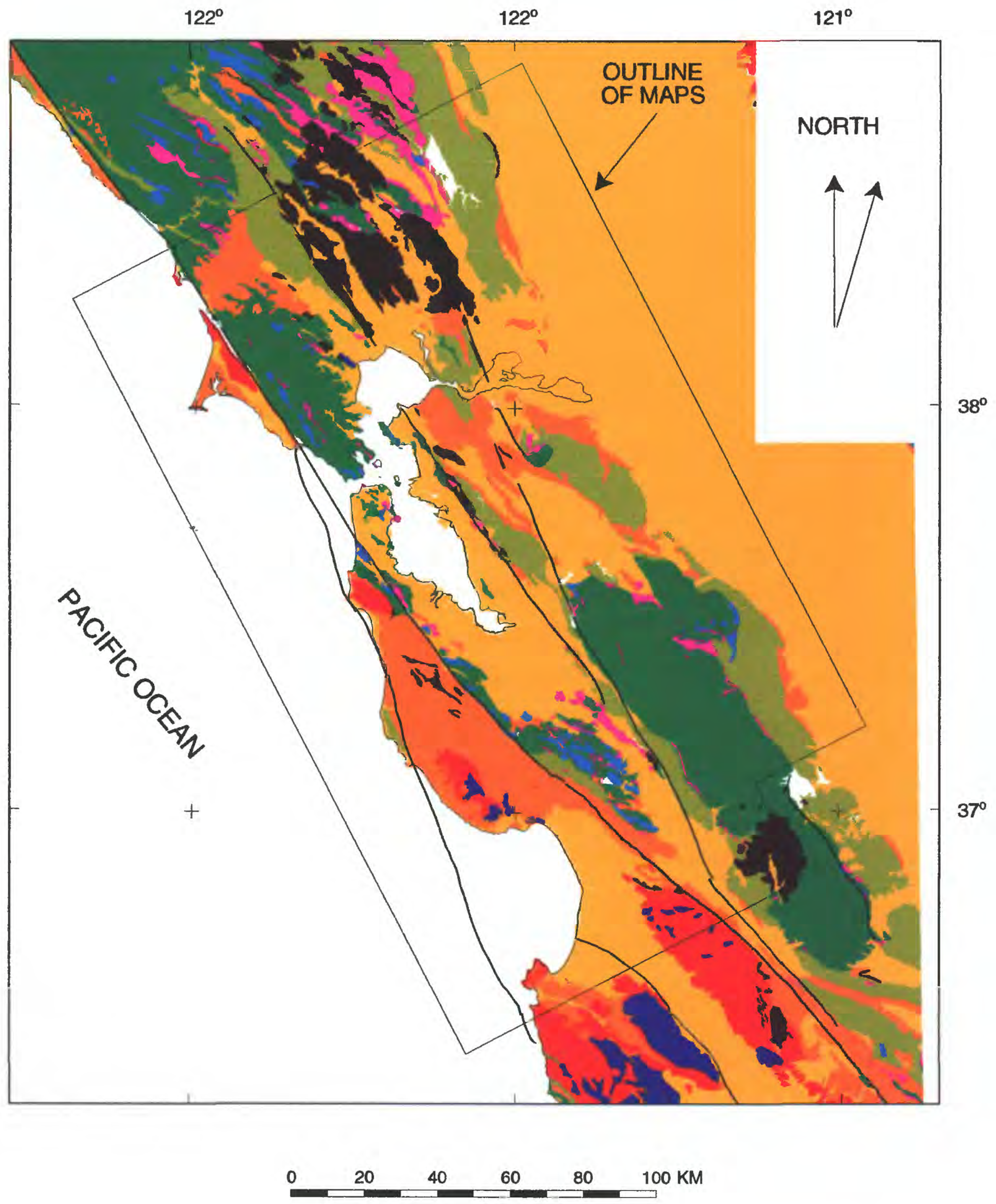




\section{GEOLOGY OF THE BAY AREA}

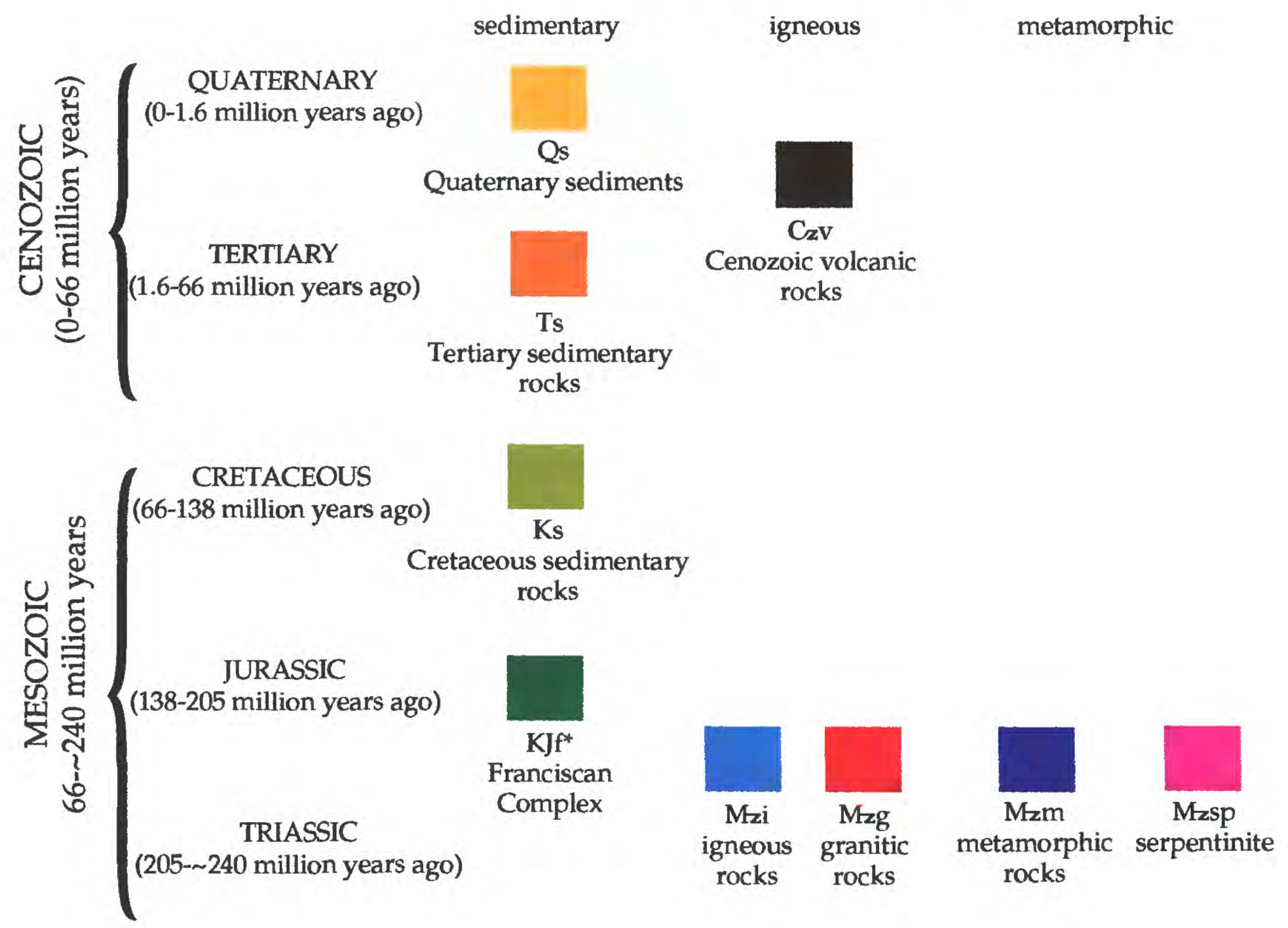

A geologic map shows the distribution of rocks exposed on the surface. The chart above is a key to the geologic units shown on the color geologic map. The units are ordered by age (the vertical axis) and rock type (the horizontal axis). See Table 1 for a list of the densities and magnetic properties of each geologic unit.

Sedimentary rocks are formed by the weathering or erosion of older rocks and by biogenic ("life") processes (e.g., rocks consisting of seashells). Igneous rocks are formed by the cooling of molten rock or magma. Volcanic rocks are igneous rocks that have been extruded onto the surface of the Earth whereas plutonic rocks cooled beneath the Earth's surface. Granitic rocks are plutonic rocks that are rich in silica and aluminum; they include the light-colored rocks that form the much of the Sierra Nevada. Metamorphic rocks are rocks that have been altered by heat or pressure.

*Unit KJf (Franciscan Complex) also includes some igneous rocks. 